\title{
Seismic Assessment of Asymmetric Single-storey R/C Buildings by Two New Methodologies: Enforced Displacement-Based and Forced-Based Pushover Procedures
}

\author{
Athanasios P. Bakalis *, Triantafyllos K. Makarios \\ Institute of Structural Analysis and Dynamics of Structure, School of Civil Engineering, Aristotle University of \\ Thessaloniki, GR-54124, Greece \\ E-mail: abakalis@civil.auth.gr(Correspondingauthor),makariostr@civil.auth.gr
}

Received: 28 January 2020; Accepted: 28 February 2020; Available online: 5 April 2020

\begin{abstract}
Two new documented non-linear static (pushover) procedures on asymmetric single-storey R/C buildings are presented in detail herein, aiming directly at the Near Collapse state. Both procedures apply relative to the "Capable Near Collapse Principal reference system" of the single-storey building. The main objective of the two proposed procedures is to fully consider the coupling between torsional and translational vibrations of the floor-diaphragm under translational seismic excitation of the building's base. The first pushover procedure, which is a Direct Displacement-Based one, uses floor enforced-displacements as action. In the second pushover procedure, which is a Force-Based one, the floor lateral static forces are applied eccentrically to centre of mass using suitable inelastic design eccentricities (dynamic plus accidental ones). The floor enforcedtranslations/rotation and the appropriate inelastic dynamic eccentricities used in the two proposed procedures derive from extensive parametric non-linear response history analysis and are given by figures or equations. In order to clarify in detail and evaluate the new pushover procedures, a torsionally-flexible, double-asymmetric, single-storey $\mathrm{R} / \mathrm{C}$ building is seismically assessed. The validation of both procedures relative to the results of nonlinear response history analysis shows that both predict with safety the in-plan displacements of the building.

Keywords: Non-linear static analysis; Pushover procedure; Response history analysis; Inelastic dynamic eccentricities; Floor enforced-displacements; Capable near collapse centre of stiffness; Torsionally-flexible buildings.
\end{abstract}

\section{Introduction}

The main method for the seismic assessment of an R/C building is the non-linear static (pushover) method of analysis. The application of pushover method according to various seismic codes, such as Eurocode EN 1998 [1,2], shows several drawbacks. First, by applying the floor lateral static force on the location of the Centre of Mass (CM) that is shifted by the accidental eccentricity, the phenomenon of the development of floor-diaphragm torsional vibration about vertical axis coupled to translational ones cannot be rationally considered. With other words, this phenomenon, occurring both in linear and in non-linear areas, is seriously underestimated, especially in torsionally-flexible buildings, because of the inability to obtain the actual inertial torsional moment of the floordiaphragm [3-10]. Second, EN 1998-1 does not provide any detailed information about the building principal axes and refers to the international literature (although it is emphasized at various points that the lateral loads should be applied along the principal axes of the building) and thus it is unclear which is the appropriate orientation of the lateral static forces in the framework of pushover analysis.

In order to overcome the abovementioned deficiencies, two new pushover procedures on single-storey R/C buildings are proposed, aiming directly at the Near Collapse (NC) state. The proposed procedures apply on all single-storey buildings providing that they have enough ductility and the possibility of floor plastic mechanism formation has been blocked out. The first pushover procedure is a Direct Displacement-Based one under which floor enforced-displacements are applied, as the action vector. In detail, two enforced-translations along two ideal principal axes and one enforced-rotation about vertical axis are applied with appropriate combinations to consider the spatial seismic action. In the framework of the second proposed pushover procedure [3,4], which is a ForcedBased one, the application point of the floor lateral static force in the building plan is determined using suitable inelastic dynamic eccentricities. Two different loading locations in the floor-diaphragm are considered along each principal direction. The first one is towards the stiff side of the building while the second one is towards the flexible side of the building. As is well known, two inertial seismic forces along $\mathrm{x}, \mathrm{y}$ axes and an inertial seismic moment 
about vertical axis are developed on the $\mathrm{CM}$ of the floor-diaphragm during the dynamic response of the singlestorey building. The seismic resultant force from the composition of these forces/moment always passes eccentric to $\mathrm{CM}$, at a distance which is called as the dynamic eccentricity. According to the proposed Forced-Based procedure, both in recent work [3-7] and the current one, where a numerical example is presented, the abovementioned dynamic eccentricity is treated in a direct way, as in other proposed methods [8-10]. Both proposed pushovers are applied with reference to the "Capable Near Collapse Principal system $\mathrm{CR}_{\mathrm{sec}}\left(I_{\mathrm{sec}}\right.$, $\left.I I_{\mathrm{sec}}, I I I_{\mathrm{sec}}\right)$ ", which is an ideal $3 \mathrm{D}$ inelastic principal system at the NC state, where its origin coincides with the inelastic centre of stiffness $\mathrm{CR}_{\mathrm{sec}}$ and the two orthogonal horizontal axes coincide with the inelastic principal axes $I_{\text {sec }}$ and $I I_{\text {sec }}$ of the single-storey building, where all its structural members have been provided with their secant stiffness $E I_{\text {sec }}$ at yield. Therefore, in order to apply the two proposed pushover procedures the following must be calculated: (a) the origin $\mathrm{CR}_{\mathrm{sec}}$ for the application of the floor enforced-displacements or for the measurement of the inelastic dynamic eccentricities, (b) the orientation of the horizontal axes $I_{\mathrm{sec}}$ and $I I_{\mathrm{sec}}$ as the appropriate orientation of the floor enforced-displacements or of the floor lateral static force and (c) the magnitude of the enforced-displacements or of the inelastic dynamic eccentricities. This is the threefold objective of the present paper, where the theoretical analysis has been given in Bakalis \& Makarios [3].

\section{Methodology}

An extended parametric analysis by non-linear response history calculations [3,4] was made under the framework of the first Author's Doctoral Thesis that is in full progress now, considering also the recently international literature review [8-12]. The main conclusions and the proposed methodology are summarized below:

1) The most suitable building model for the application of non-linear analysis, aiming directly at the NC state, is established considering the secant stiffness at yield $\left(E I_{\text {sec }}\right)$ of all structural members end-sections [2-4]. In this way, the in-plan stiffness and strength distribution are rationally considered. Therefore, the secant lateral stiffness at yield of the building, $K_{\mathrm{sec}}$, is calculated assuming that all the extreme member sections have yielded, i.e. considering that all structural members (columns, beams, walls and cores) have been developed plastic hinges at their critical end-sections (full Near Collapse state).

2) The most appropriate point (almost independent of the loading) that must be the origin for measuring the new inelastic dynamic eccentricities of the proposed Forced-Based pushover procedure is the "Capable Near Collapse Centre of Stiffness" $\mathrm{CR}_{\mathrm{sec}}$ resulting from the above model of conclusion (1). $\mathrm{CR}_{\text {sec }}$ is used also as the application point of the floor enforced-translations of the proposed Displacement-Based pushover procedure.

3) The most appropriate orientation of the floor horizontal static force (almost independent of the loading) of the proposed Forced-Based pushover procedure is along the directions of the horizontal "Capable Near Collapse Principal Axes" $I_{\text {sec }}$ and $I I_{\text {sec }}$ resulting from the above model of conclusion (1). Also, the floor enforcedtranslations of the Displacement-Based pushover procedure are oriented along the inelastic principal axes $I_{\text {sec }}$ and $I I_{\text {sec }}$.

4) The control of the building torsional sensitivity must be performed in the above model of conclusion (1). The asymmetric single-story buildings are divided into two categories: (a) buildings with torsional sensitivity when $r_{\mathrm{I} \text {,sec }}$ or $r_{\mathrm{II}, \mathrm{sec}} \leq 1.10 r_{\mathrm{m}}$ applies and (b) buildings without torsional sensitivity when $r_{\mathrm{I}, \mathrm{sec}}$ and $r_{\mathrm{II}, \mathrm{sec}}>1.10 r_{\mathrm{m}}$ applies, where $r_{\mathrm{I}, \mathrm{sec}}$ and $r_{\mathrm{II}, \mathrm{sec}}$ are the "Capable Near Collapse Torsional Radii" in respect to the axes $I_{\text {sec }}$ and $I I_{\text {sec }}$ respectively and $r_{\mathrm{m}}$ is the radius of gyration of the floor-diaphragm.

5a) In the framework of the proposed Direct Displacement-Based pushover procedure, the floor enforcedtranslations $\psi_{\mathrm{I} \text {,sec }}$ and $\psi_{\mathrm{II}, \mathrm{sec}}$, that are applied on the location of $\mathrm{CR}_{\mathrm{sec}}$ along the $I_{\mathrm{sec}}$ and $I I_{\mathrm{sec}}$ axes, are calculated from the proposed (mean) values of floor inelastic angular deformations shown in Figure 1 (including trendlines) for three categories of single-storey buildings. The first category consists of pure Frame buildings (without walls), the second category consists of pure Wall buildings and coupled (via beams) Wall buildings, while the third category includes Dual buildings (equivalent to frame or wall buildings). The values of Figure 1 are given separately for the two torsional sensitivity cases of step 4 and for various normalized static eccentricities $e_{\mathrm{R}} / L$, where $e_{\mathrm{R}}$ and $L$ are the static eccentricity and the plan length along the inelastic principal axes $I_{\mathrm{sec}}$ or $I I_{\mathrm{sec}}$ respectively. The floor inelastic angular deformation $\gamma_{\mathrm{CRsec}}$ is equal to the ratio $\psi_{\mathrm{CRsec}} / H$, where $\psi_{\mathrm{CRsec}}$ is the translational displacement of $\mathrm{CR}_{\mathrm{sec}}$ along the axis $I_{\mathrm{sec}}$ or $I I_{\mathrm{sec}}$ and $H$ is the building height. The definition of the floor enforced-displacements is given in Figure 2.

According to the proposed Direct Displacement-based pushover procedure, in order to predict the seismic demands of the building flexible and stiff sides, the (mean) floor enforced-rotations $\psi_{\mathrm{R}, \text { flex }}$ and $\psi_{\mathrm{R}, \text { stif }}$ about vertical axis are used respectively, as proposed by Figure 3 for the three abovementioned categories of singlestorey buildings. The proposed values depend on the torsional sensitivity ( 2 cases of step 4 ) and the normalized static eccentricitiy $e_{\mathrm{R}} / L$ of the single-storey building along axis $I_{\mathrm{sec}}$ or $I I_{\mathrm{sec}}$. The maximum selected values of floor enforced-rotations between the two principal directions are used in the load combinations following. 


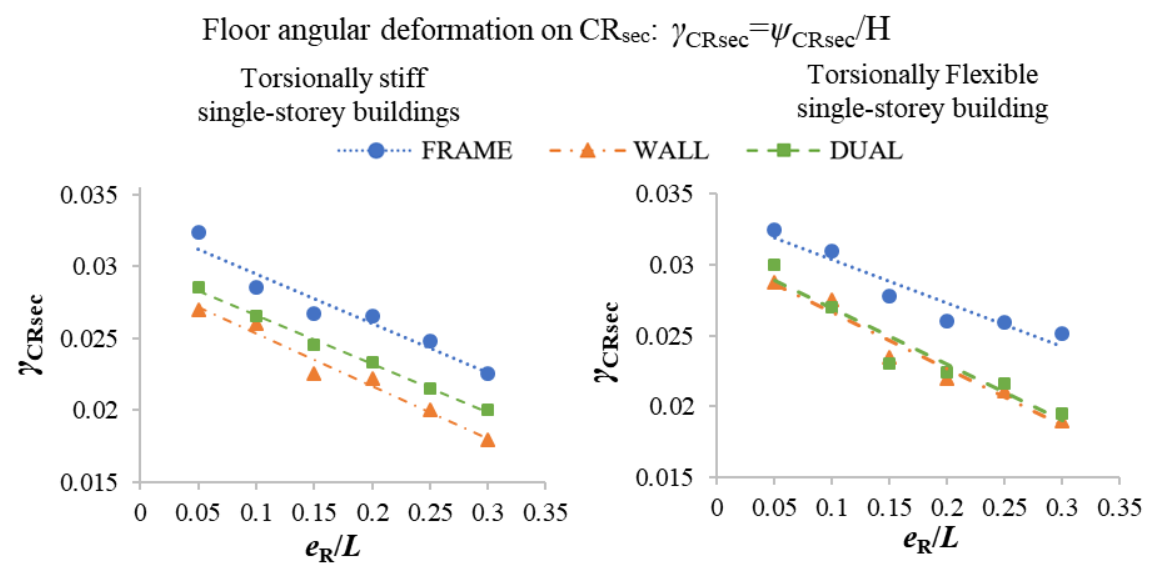

Figure 1. Inelastic angular floor deformation $\gamma_{\mathrm{CRsec}}$ on $\mathrm{CR}_{\mathrm{sec}}$ along the $I_{\mathrm{sec}}$ or $I I_{\mathrm{sec}}$ axes used in the calculation of the enforced-translations $\psi_{\mathrm{I} \text {,sec }}$ or $\psi_{\mathrm{II}, \mathrm{sec}}$ of the proposed Direct Displacement-Based pushover.

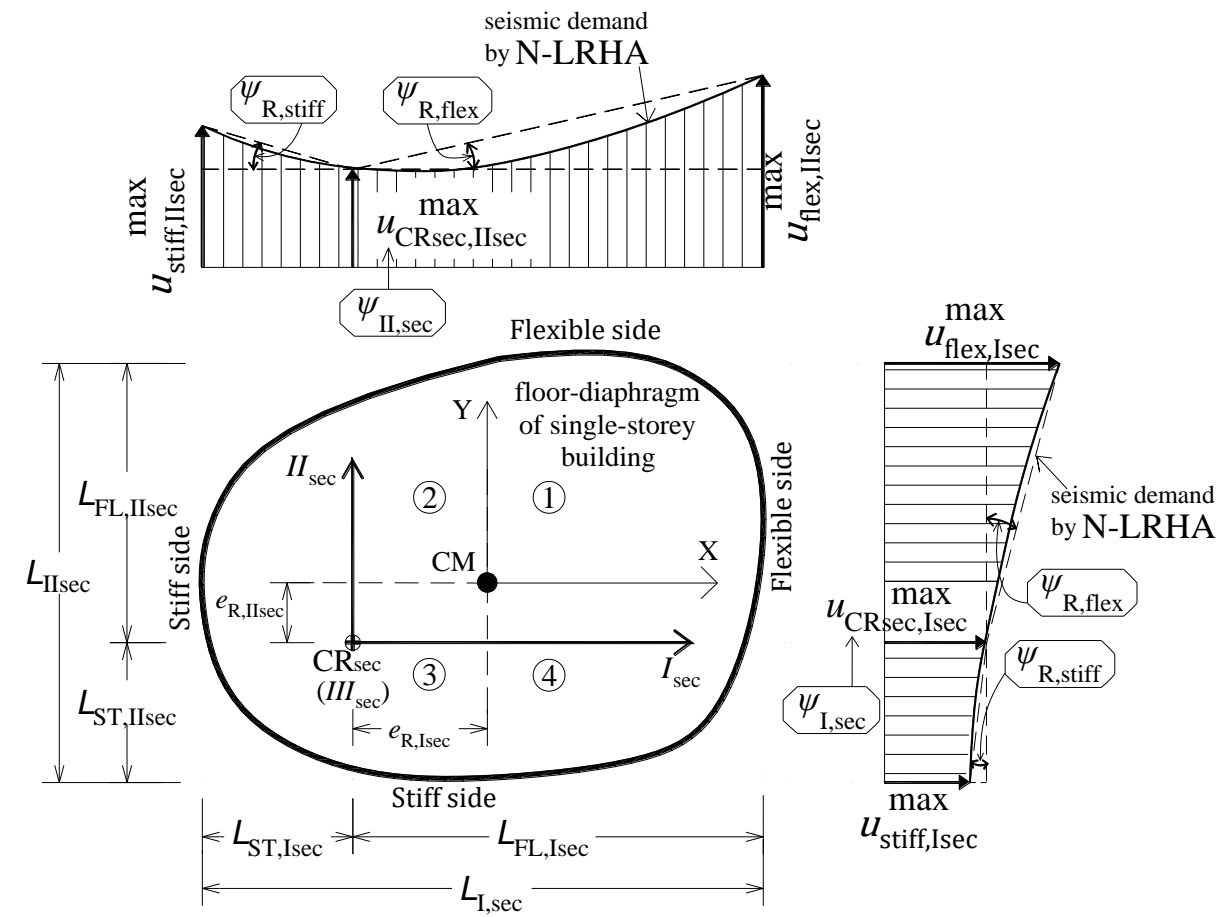

Figure 2. Definition of the floor-enforced displacements of the proposed Direct Displacement-Based pushover. Two floor enforced-translations $\psi_{\mathrm{I} \text {,sec }}$ and $\psi_{\mathrm{II} \text {,sec }}$ on $\mathrm{CR}_{\text {sec }}$ along the $I_{\mathrm{sec}}$ and $I I_{\text {sec }}$ axes and a floor enforcedrotation $\psi_{\mathrm{R}, \text { flex }}$ or $\psi_{\mathrm{R}, \text { stif }}$ about vertical axis.

5b) To consider the spatial seismic action in the framework of the proposed Direct Displacement-Based pushover analysis, the floor enforced-translations are obtained as follows: each floor enforced-translation on $\mathrm{CR}_{\mathrm{sec}}$ in one examined principal direction $\left(\psi_{\mathrm{I} \text {.sec }}\right.$ or $\left.\psi_{\mathrm{II}, \mathrm{sec}}\right)$ and a simultaneous floor enforced-translation equal to $30 \%$ of its full value in the other principal direction $\left(0.3 \cdot \psi_{\mathrm{I}, \mathrm{sec}}\right.$ or $\left.0.3 \cdot \psi_{\mathrm{II}, \mathrm{sec}}\right)$. Moreover, the floor enforced-rotation about vertical axis, $\psi_{\mathrm{R}, \text { stiff }}$ or $\psi_{\mathrm{R}, \mathrm{flex}}$, is also considered. It is noted that $\psi_{\mathrm{R}, \text { stiff }}$ or $\psi_{\mathrm{R}, \text { flex }}$ is inserted in each loading combination with the appropriate sign ( + or - ) in order to increase (or decrease as regards $\psi_{\mathrm{R}, \text { stiff }}$ ) the ductility demand of the stiff or flexible side of the building along the examined principal direction, where sign $(+)$ means counter-clockwise direction. The appropriate sign depends on the in-plan location of $\mathrm{CR}_{\mathrm{sec}}$ relative to $\mathrm{CM}$, which defines the stiff and flexible sides of the single-storey building. With reference to Figure 2, this location can be inside one of the four quadrants marked 1 to 4 in circle. The possible signs of the enforced-rotations are shown in Table 1, where the stiff side translational displacement along the examined principal direction is considered higher than the corresponding of $\mathrm{CR}_{\text {sec }}$ (otherwise, in the case where the $\psi_{\mathrm{R}, \text { stiff }}$ value from Figure 3 is negative, the sign 
for $\psi_{\mathrm{R}, \text { stiff }}$ is reversed in Table 1). Considering the $( \pm)$ signs of action, sixteen (16) possible loading combinations may be obtained shown in Tables 2 and 3 along each main (examined) principal direction $I_{\text {sec }}$ or $I I_{\text {sec }}$, separately (index "sec" has been omitted). It is noted that, in Tables 2 and 3 the signs of the enforced-rotations $\psi_{\mathrm{R}, \text { stiff }}$ and $\psi_{\mathrm{R}, \text { flex }}$ have been adjusted to the in-plan location of $\mathrm{CR}_{\mathrm{sec}}$ shown in Figure 2 (inside quadrant 3 ) and it is considered also that the selected $\psi_{\mathrm{R} \text {,stiff }}$ value from Figure 3 is positive. In other cases, the appropriate signs are selected from Table 1. The envelope of the results of the sixteen (16) separate enforced-displacement pushovers is considered as the seismic demand.
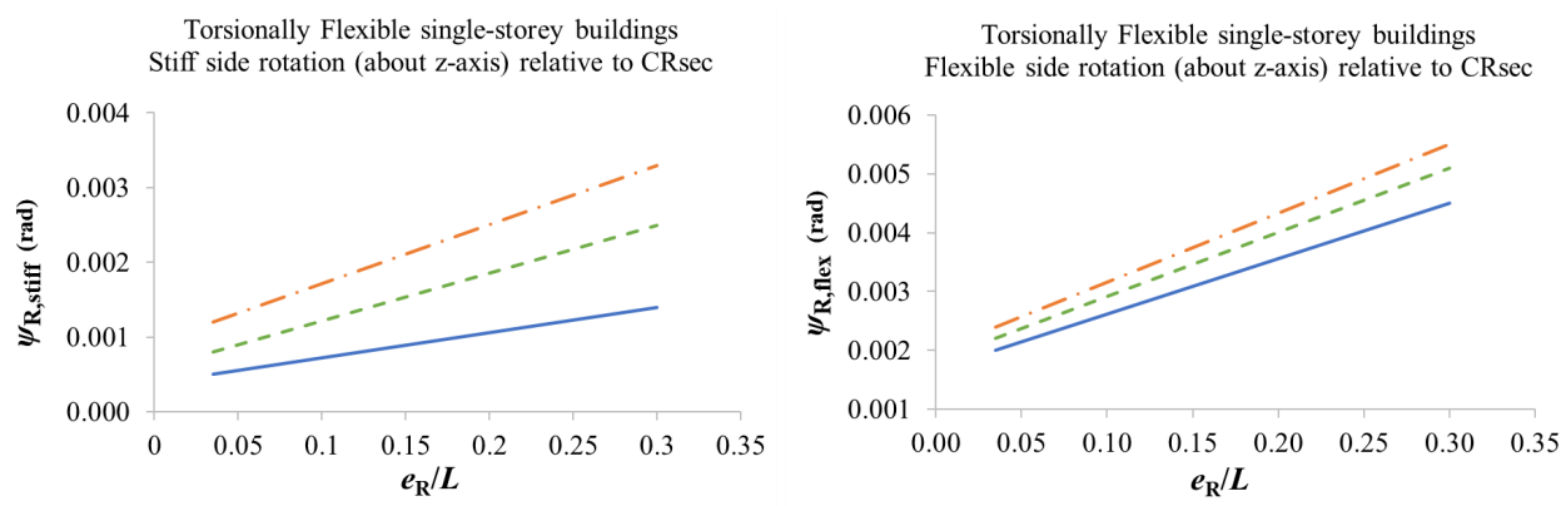

Torsionally Stiff single-storey buildings Stiff side rotation (about $\mathrm{Z}$-axis) relative to $\mathrm{CRsec}$

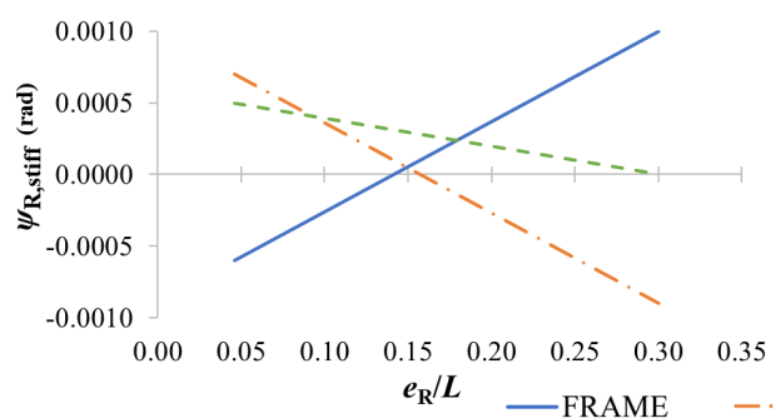

Torsionally Stiff single-storey buildings Flexible side rotation (about $\mathrm{z}$-axis) relative to $\mathrm{CRsec}$

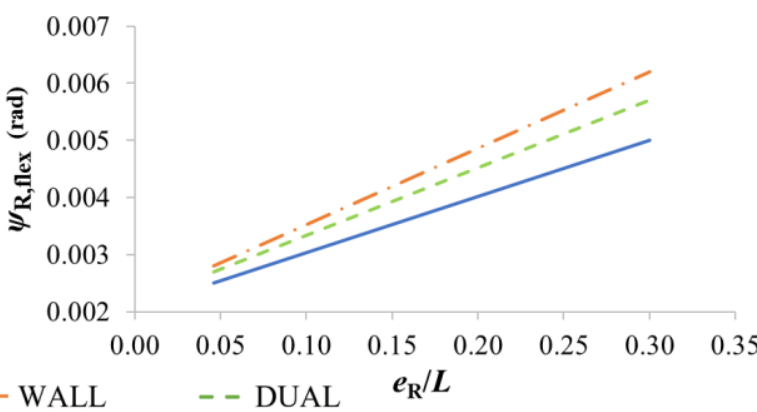

Figure 3. Floor enforced-rotation $\psi_{\mathrm{R}, \text { flex }}$ and $\psi_{\mathrm{R}, \mathrm{stiff}}(\mathrm{rad})$ about vertical axis of the proposed Direct DisplacementBased pushover in order to predict the seismic demand of the flexible and stiff sides.

Table 1. Sign of floor enforced-rotations $\psi_{\mathrm{R}, \text { flex }}$ and $\psi_{\mathrm{R} \text {,stiff }}$ inside the loading combos of Tables 2 and 3 with reference to the possible $\mathrm{CR}_{\text {sec }}$ in-plan location shown in Figure 2 (quadrants 1-4), where the stiff side displacement is considered higher than $\mathrm{CR}_{\mathrm{sec}}$.

\begin{tabular}{|c|c|c|c|c|c|c|c|c|}
\hline \multirow{3}{*}{$\begin{array}{l}\text { Main Principal Direction } \\
\text { in (16) loading combos }\end{array}$} & \multicolumn{8}{|c|}{$\mathrm{CR}_{\text {sec }}$ in-plan position inside Quadrant: } \\
\hline & \multicolumn{2}{|l|}{1} & \multicolumn{2}{|l|}{2} & \multicolumn{2}{|l|}{3} & \multicolumn{2}{|l|}{4} \\
\hline & $\psi_{\mathrm{R}, \text { stiff }}$ & $\psi_{\mathrm{R}, \mathrm{flex}}$ & $\psi_{\mathrm{R}, \text { stiff }}$ & $\psi_{\mathrm{R}, \mathrm{flex}}$ & $\psi_{\mathrm{R}, \mathrm{stiff}}$ & $\psi_{\mathrm{R}, \mathrm{flex}}$ & $\psi_{\mathrm{R}, \mathrm{stiff}}$ & $\psi_{\mathrm{R}, \mathrm{flex}}$ \\
\hline$I_{\text {sec }}$ & - & + & - & + & + & - & + & - \\
\hline$-I_{\text {sec }}$ & + & - & + & - & - & + & - & + \\
\hline$I I_{\text {sec }}$ & + & - & - & + & - & + & + & - \\
\hline$-I I_{s e c}$ & - & + & + & - & + & - & - & + \\
\hline
\end{tabular}

Table 2. Earthquake Spatial Action of simultaneous floor enforced-displacements, where the displacement along axis $I_{\text {sec }}$ is maximized $\left(\mathrm{CR}_{\mathrm{sec}}\right.$ in-plan position inside quadrant 3, Figure 2)

\begin{tabular}{|c|c|}
\hline Eight (8) enforced-displacement com & ear static analysis \\
\hline 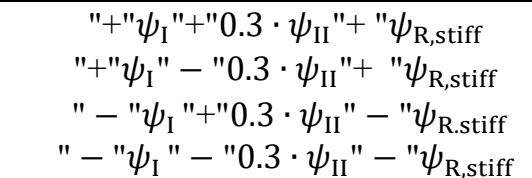 & $\begin{array}{c}"+\psi_{\mathrm{I}} "+0.3 \cdot \psi_{\mathrm{II}} "-" \psi_{\mathrm{R}, \mathrm{flex}} \\
"+" \psi_{\mathrm{I}} "-" 0.3 \cdot \psi_{\mathrm{II}} "-" \psi_{\mathrm{R}, \mathrm{flex}} \\
"-" \psi_{\mathrm{I}} "+" 0.3 \cdot \psi_{\mathrm{II}} "+" \psi_{\mathrm{R}, \mathrm{flex}} \\
"-" \psi_{\mathrm{I}} "-" 0.3 \cdot \psi_{\mathrm{II}} "+" \psi_{\mathrm{R}, \mathrm{flex}}\end{array}$ \\
\hline
\end{tabular}


Table 3. Earthquake Spatial Action of simultaneous floor enforced-displacements, where the displacement along axis $I I_{\text {sec }}$ is maximized ( $\mathrm{CR}_{\text {sec }}$ in-plan position inside quadrant 3 , Figure 2$)$

\begin{tabular}{|c|c|}
\hline \multicolumn{2}{|c|}{ Eight (8) enforced-displacement combinations of non-linear static analysis } \\
\hline 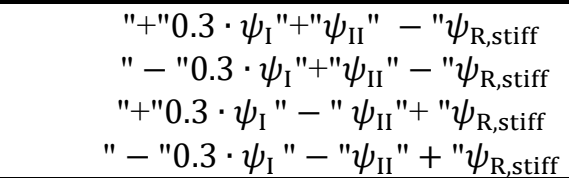 & 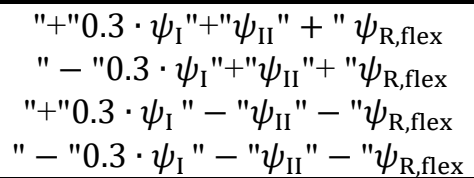 \\
\hline
\end{tabular}

6a) The appropriate inelastic dynamic eccentricities $e_{\text {stiff }}$ and $e_{\text {flex }}$ of the proposed Forced-Based pushover procedure, for the building stiff and flexible side respectively, along each horizontal "Capable Near Collapse Principal Axis" $I_{\mathrm{sec}}$ or $I I_{\mathrm{sec}}$, have been determined from statistical processing on the results of an extended parametric analysis and are given through Figure 4 and Equations (1-4) (prediction lines with a suitable standard deviation).
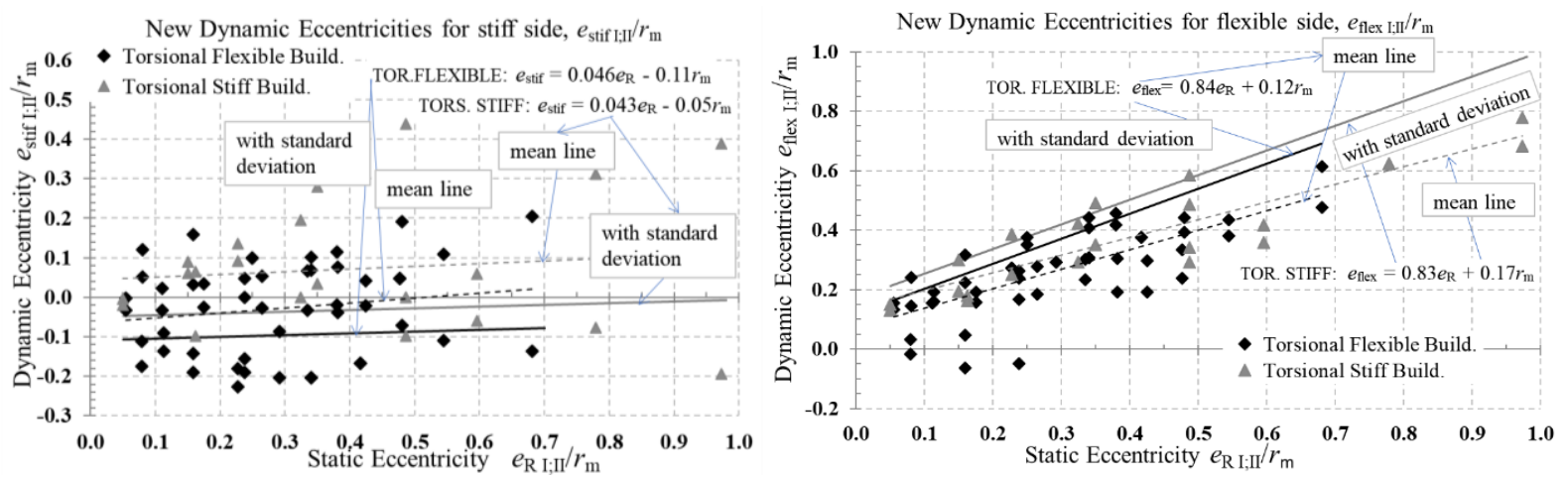

Fig. 4. Normalized inelastic dynamic eccentricities, $e_{\text {stif I;II }} / r_{\mathrm{m}}$ for the stiff side (left) and $e_{\text {flex I;II }} / r_{\mathrm{m}}$ for the flexible side (right)

For buildings with Torsional Sensitivity, i.e. when $r_{\mathrm{I}, \mathrm{sec}}$ or $r_{\mathrm{II}, \mathrm{sec}} \leq 1.10 r_{\mathrm{m}}$ :

$$
\begin{aligned}
& e_{\mathrm{stiff}, i}=0.046 \cdot e_{\mathrm{R}, i}-0.11 \cdot r_{m} \\
& e_{\mathrm{flex}, i}=0.84 \cdot e_{\mathrm{R}, i}+0.12 \cdot r_{\mathrm{m}}
\end{aligned}
$$

For buildings without Torsional Sensitivity, i.e. when $r_{\mathrm{I}, \mathrm{sec}}$ and $r_{\mathrm{I}, \mathrm{sec}}>1.10 r_{\mathrm{m}}$ :

$$
\begin{aligned}
& e_{\mathrm{stiff}, i}=0.043 \cdot e_{\mathrm{R}, i}-0.05 \cdot r_{\mathrm{m}} \\
& e_{\mathrm{flex}, i}=0.83 \cdot e_{\mathrm{R}, i}+0.17 \cdot r_{\mathrm{m}}
\end{aligned}
$$

where the index $i$ refers to the examined horizontal direction $I_{\mathrm{sec}}$ or $I I_{s e c}$ and $e_{\mathrm{R}, i}$ is the corresponding inelastic static (or stiffness) eccentricity $\left(\mathrm{CR}_{\mathrm{sec}}\right.$ in-plan position relative to $\left.\mathrm{CM}\right)$.

6b) The proposed Forced-Based procedure for the documented application of pushover analysis on asymmetric single-storey R/C buildings uses the inelastic design eccentricities. Noting that the inelastic design eccentricities $e_{1}, e_{2}$ (Equations 5-6) and $e_{3}, e_{4}$ (Equations 7-8) are used for loading along the "Capable Near Collapse Principal Axes" $I I_{\text {sec }}$ and $I_{\text {sec }}$ respectively, all measured from the "Capable Near Collapse Centre of Stiffness" CR sec and with positive direction towards the Mass Centre CM. The calculation of the inelastic design eccentricities is achieved combining the new inelastic dynamic eccentricities, resulting from Equations (1-4), with the floor accidental eccentricities $e_{\mathrm{a}, i}$ obtained in such a way that the final position of the floor horizontal static force to be more eccentric relative to the Mass Centre CM.

$$
\begin{aligned}
& e_{1}=e_{\mathrm{flex}, I \mathrm{sec}}+e_{\mathrm{a}, I \mathrm{sec}} \\
& e_{2}=e_{\mathrm{stiff}, I \mathrm{sec}}-e_{\mathrm{a}, I \mathrm{sec}} \\
& e_{3}=e_{\mathrm{flex}, I I \mathrm{sec}}+e_{\mathrm{a}, I I \mathrm{sec}} \\
& e_{4}=e_{\mathrm{stiff}, I I \mathrm{sec}}-e_{\mathrm{a}, I I \mathrm{sec}}
\end{aligned}
$$


where $e_{\text {stiff,Isec }}, e_{\text {flex,Isec }}$ and $e_{\text {stiff,IIsec }}, e_{\text {flex }, I I s e c}$ are the inelastic dynamic eccentricities from Equations (1-4) along the examined principal directions $I_{\text {sec }}$ and $I I_{\text {sec }}$ respectively while the accidental eccentricities are determined from equations $e_{\mathrm{a}, I \mathrm{sec}}= \pm(0.05 \sim 0.10) \cdot L_{I \mathrm{sec}}$ and $e_{\mathrm{a}, I I \mathrm{sec}}= \pm(0.05 \sim 0.10) \cdot L_{I I \sec }$ according to EN1998-1, where $L_{I \mathrm{sec}}$ and $L_{I I \text { sec }}$ are the maximum floor plan dimension normal to the loading direction.

$6 c)$ Considering the two signs $( \pm)$ of application of the floor lateral static forces, eight separate pushover analyses are performed. The final results from the spatial action of the earthquake are computed as proposed by Eurocode EN 1998-1, i.e. by the SRSS combinations on the results of the eight separate pushover analyses (sixteen loading combinations). These combinations are carried out in that step of the separate pushover analyses where the "seismic target-displacement" of the diaphragm loading point occurs. It is noted that the capacity curve of the building, along the horizontal axis under consideration $\left(I_{\mathrm{sec}}\right.$ or $\left.I I_{\mathrm{sec}}\right)$, is given by the corresponding base shear and the displacement of the diaphragm point where the floor lateral static force is applied.

The abovementioned (2), (3) and (4) are calculated as follows:

a) From a temporary static linear analysis of the model with a static unit floor moment about vertical axis, e.g. $M_{z}=1.00 \mathrm{kNm}$, the lateral displacements $u_{\mathrm{x}, \mathrm{CM}, M_{z}}, u_{\mathrm{y}, \mathrm{CM}, M_{z}}$ of the Mass Centre CM along the $\mathrm{x}$-axis and y-axis respectively and the rotation $\theta_{\mathrm{z}, M_{z}}$ of the diaphragm about z-axis are calculated. The coordinates $x_{\mathrm{CR}, \mathrm{sec}}, y_{\mathrm{CR}, \mathrm{sec}}$ of the "Capable Near Collapse Centre of Stiffness" $\mathrm{CR}_{\mathrm{sec}}$, relative to the Mass Centre, are calculated from Equations $(9 \mathrm{a}, \mathrm{b})[13,14]$ :

$$
x_{\mathrm{CR}, \mathrm{sec}}=-u_{\mathrm{y}, \mathrm{CM}, M_{\mathrm{z}}} / \theta_{\mathrm{z}, M_{z}}, y_{\mathrm{CR}, \mathrm{sec}}=+u_{\mathrm{x}, \mathrm{CM}, M_{\mathrm{z}}} / \theta_{\mathrm{z}, M_{\mathrm{z}}}
$$

b) From a temporary static linear analysis of the model with a lateral static unit force $F_{\mathrm{x}}=1.00 \mathrm{kN}$ that is located on $\mathrm{CR}_{\mathrm{sec}}$ along $\mathrm{x}$-axis, the displacement $u_{\mathrm{x}, F_{\mathrm{x}}}$ of $\mathrm{CR}_{\mathrm{sec}}$ along the $\mathrm{x}$-axis is calculated. Similar, from a temporary static linear analysis with a lateral static unit force $F_{\mathrm{y}}=1.00 \mathrm{kN}$ that is located on $\mathrm{CR}_{\mathrm{sec}}$ along y-axis, the displacements $u_{y, F_{\mathrm{y}}}$ and $u_{\mathrm{x}, F_{\mathrm{y}}}$ of $\mathrm{CR}_{\mathrm{sec}}$ along the $\mathrm{y}$-axis and $\mathrm{x}$-axis respectively are calculated. The orientation (angle $a$ ) of the horizontal "Capable Near Collapse Principal Axes" $I_{\text {sec }}$ and $I I_{\text {sec }}$, relative to the initial x and y axes respectively, is calculated from Equation (10) [13,14]:

$$
\tan 2 a=\frac{2 u_{\mathrm{x}, F_{\mathrm{y}}}}{u_{\mathrm{x}, F_{\mathrm{x}}}-u_{\mathrm{y}, F_{\mathrm{y}}}}
$$

c) From a temporary static linear analysis of the model with a lateral static unit force $F_{\mathrm{II}}=1.00 \mathrm{kN}$ that is located on $\mathrm{CR}_{\text {sec }}$ along axis $I I_{\text {sec }}$, the displacement $u_{\mathrm{II}, F_{\mathrm{II}}}$ of $\mathrm{CR}_{\mathrm{sec}}$ along the $I I_{\text {sec }}$ axis is calculated. Also, from a second temporary static linear analysis, where the lateral static unit force $F_{\mathrm{I}}=1.00 \mathrm{kN}$ is located on $\mathrm{CR}_{\text {sec }}$ along axis $I_{\text {sec }}$, the displacements $u_{\mathrm{I}, F_{\mathrm{I}}}$ of $\mathrm{CR}_{\mathrm{sec}}$ along the $I_{\mathrm{sec}}$ axis is calculated. With known rotation $\theta_{\mathrm{z}, M_{z}}$ due to the static unit floor moment $M_{z}=1.00 \mathrm{kNm}$ about vertical axis, the building "Capable Near Collapse Torsional Radii" $r_{\mathrm{I}, \mathrm{sec}}$ and $r_{\mathrm{II}, \mathrm{sec}}$ along the two axes $I_{\mathrm{sec}}$ and $I I_{\mathrm{sec}}$ respectively are calculated from Equations (11a, b) [15]:

$$
r_{\mathrm{I}, \mathrm{sec}}=\sqrt{\frac{u_{\mathrm{II}, \mathrm{F}}}{\theta_{\mathrm{Z}, M_{z}}}} \quad, \quad r_{\mathrm{II}, \mathrm{sec}}=\sqrt{\frac{u_{\mathrm{I}, \mathrm{F}_{\mathrm{I}}}}{\theta_{\mathrm{z}, M_{z}}}}
$$

\section{Numerical example}

In this section, an example of an asymmetric single-storey $\mathrm{R} / \mathrm{C}$ building is presented to demonstrate clearly and in detail the application steps of the two proposed pushover analysis procedures using either floor enforceddisplacements or design eccentricities. Finally, the results of this numerical example will be used in order to validate the proposed pushover procedures.

\subsection{Building characteristics}

Consider the building as illustrated in Figure 5, which is a reinforced concrete (R/C), double-asymmetric, singlestorey building with construction materials $\mathrm{C} 25 / 30$ for the concrete and B500c for the steel of average strengths $f_{\mathrm{cm}}=33 \mathrm{MPa}$ and $f_{\mathrm{ym}}=550 \mathrm{MPa}$, respectively. In Table 4, the elastic and inertial characteristics of the building as well as the torsional sensitivity check of its non-linear model (in which all members are supplied with their secant stiffness $E I_{\mathrm{sec}}$ at yield) are presented. The building is characterized as torsional sensitive $\left(r_{\mathrm{I}} / r_{\mathrm{m}}<1.10\right)$. The position of the Mass Centre CM coincides with the geometric center of the floor plan. The building consists of three wings with different orientations. A rigid diaphragm of thickness $17 \mathrm{~cm}$ joins the wings and extends outwards forming a $2 \mathrm{~m}$ perimetric cantilever. The X-Y wing consists of coupled walls ( 3 walls about X and 6 walls about Y direction coupled with T-beams), the $135^{\circ}$ wing consists of five frames ( 2 frames along $135^{\circ}$ and 3 
frames normal to $135^{\circ}$ direction) and the $-135^{\circ}$ wing consists of seven frames, two of them coupled with r/c flexural walls ( 4 frames along $-135^{\circ}$ and 3 frames normal to $-135^{\circ}$ direction). The two wings at orientations $135^{\circ}$ and $-135^{\circ}$ are continuous, along their normal direction, with a common frame while the third $\mathrm{X}-\mathrm{Y}$ wing is linked to the other two by Tee beams. The structural system of the building consists of rectangular columns of dimensions $0.50 / 0.50$ $\mathrm{m}$, beams with Tee section $0.30 / 0.60 / 1.60 / 0.17 \mathrm{~m}$ and flexural walls with orthogonal section $0.30 / 1.50 \mathrm{~m}$. All the perimetric walls have one boundary or middle barbell (column 0.50/0.50 m) to satisfy the anchorage length of normal beam longitudinal bars. The height of the buildings is $3 \mathrm{~m}$.

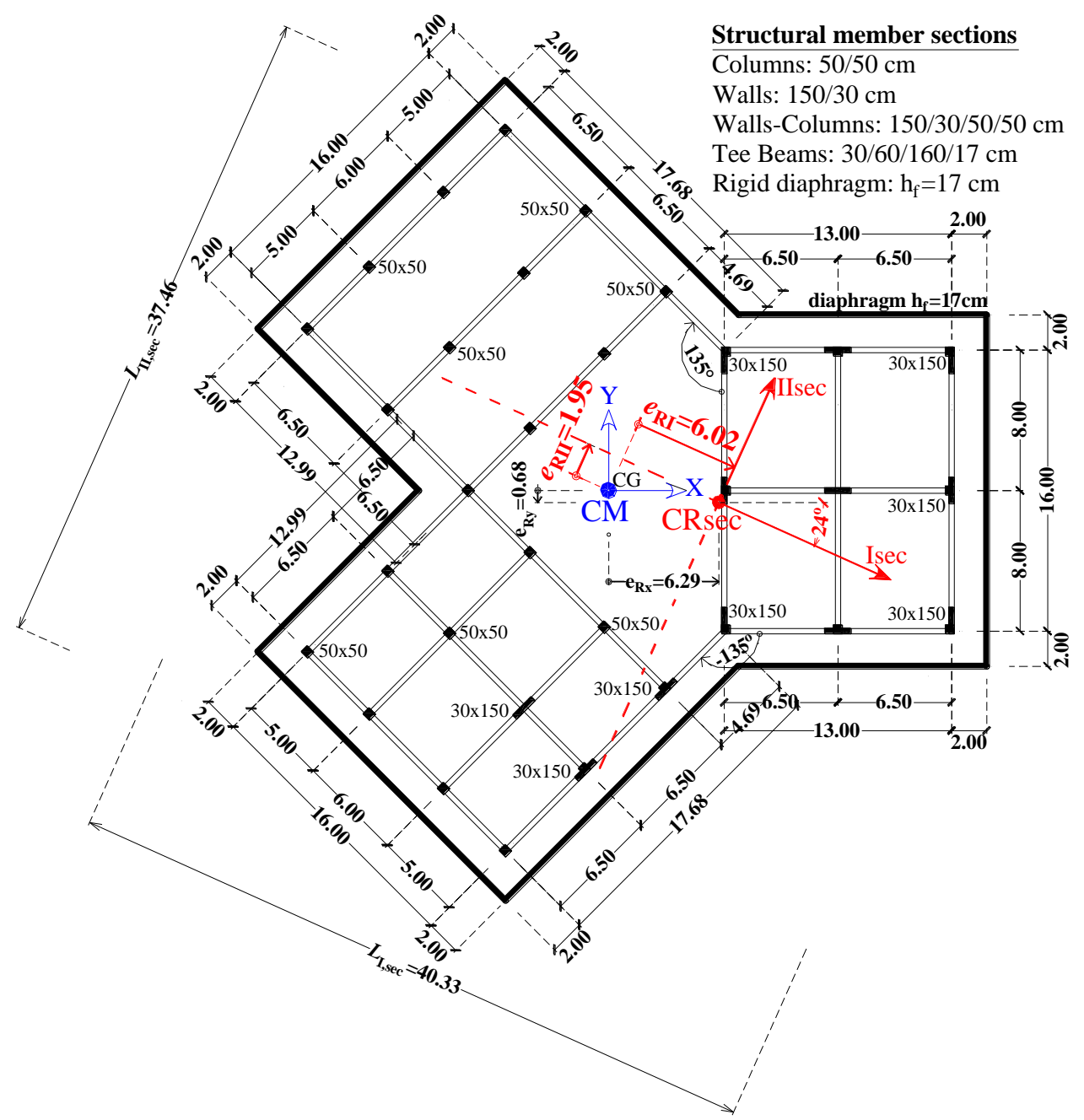

Fig. 5. Floor plan of asymmetric single-story R/C building.

Table 4. Elastic and inertial characteristics and torsional sensitivity check of the non-linear model of asymmetric single-storey R/C building with structural members provided with their secant stiffness at yield

\begin{tabular}{ll} 
Static eccentricity $e_{\mathrm{Rx}}, e_{\mathrm{Ry}}(\mathrm{m}):$ & $6.29,-0.68$ \\
Static eccentricity $e_{\mathrm{RIsec}}, e_{\mathrm{RIIsec}}(\mathrm{m}):$ & $6.02,1.95$ \\
Normalized static eccentricity $e_{\mathrm{RIsec}} / L_{\mathrm{Isec}}, e_{\mathrm{RIIsec}} / L_{\mathrm{IIsec}}:$ & $0.149,0.052$ \\
Mass $m(\mathrm{tn}):$ & 1103 \\
Mass moment of inertia $J_{\mathrm{m}}\left(\mathrm{tn} \cdot \mathrm{m}^{2}\right):$ & 222958 \\
Radius of gyration $r_{\mathrm{m}}(\mathrm{m}):$ & 14.22 \\
Torsional radius $r_{\mathrm{I}, \mathrm{sec}} \& r_{\mathrm{II}, \mathrm{sec}}(\mathrm{m}):$ & $13.32,16.27$ \\
Ratio $r_{\mathrm{I}, \mathrm{sec}} / r_{\mathrm{m}} \& r_{\mathrm{II}, \mathrm{sec}} / r_{\mathrm{m}}:$ & $0.94,1.14$ \\
Uncoupled Periods $T_{\mathrm{I}, \mathrm{sec}}, T_{\mathrm{R}}, T_{\mathrm{II}, \mathrm{sec}}(\mathrm{sec}):$ & $0.334,0.292,0.274$ \\
\hline
\end{tabular}

\subsection{Building design}

The design is performed according to the provisions of Eurocodes EN 1992-1 [16] and EN 1998-1 [1] for ductility class high (DCH). The building system is characterized as wall-equivalent dual according to EN1998-1. 
In the design model, all structural members have been provided with the effective flexural and shear stiffness equal to one-half of their corresponding uncracked (geometric) stiffness. The design model of the building is also characterized as torsional sensitive $\left(r_{\mathrm{I}, \mathrm{des}} / r_{\mathrm{m}}=0.96\right)$ and its translational uncoupled periods are about $0.15 \mathrm{sec}$ along both $\mathrm{X} \& \mathrm{Y}$-axes. The building has an importance factor $\gamma_{1}=1$ and is designed for effective peak ground acceleration $\alpha_{\mathrm{g}}=0.24 \mathrm{~g}$, soil $D$ and total behavior factor $q=3$.

\subsection{Non-linear model}

For the application of non-linear analyses, the structural members of the building model are provided with the secant moments of inertia $I_{\text {sec }}$ (at their yield). The secant stiffness $E I_{\text {sec }}$ is taken as a constant value over the entire length of each structural member, is equal to the arithmetic average of the $E I_{\text {sec }}$ values of its two end cross-sections for positive and negative bending and is given by EN 1998-3 [2]:

$$
E I_{\text {sec }}=\frac{M_{y}}{\theta_{\mathrm{y}}} \cdot \frac{L_{\mathrm{v}}}{3}
$$

For the calculation of chord rotation at yield $\theta_{\mathrm{y}}$, the equations (A.10b) and (A.11b) of EN1998-3 are used for columns-beams and walls respectively:

$$
\begin{aligned}
& \theta_{\mathrm{y}}=\varphi_{\mathrm{y}} \frac{L_{\mathrm{v}}+a_{\mathrm{v}} \cdot z}{3}+0.0013\left(1+\frac{1.5 \cdot h}{L_{\mathrm{v}}}\right)+0.13 \cdot \varphi_{\mathrm{y}} \frac{d_{\mathrm{b}} \cdot f_{\mathrm{ym}}}{\sqrt{f_{\mathrm{cm}}}} \\
& \theta_{\mathrm{y}}=\varphi_{\mathrm{y}} \frac{L_{\mathrm{v}}+a_{\mathrm{v}} \cdot z}{3}+0.002\left(1-\frac{0.125 \cdot L_{\mathrm{v}}}{h}\right)+0.13 \cdot \varphi_{\mathrm{y}} \frac{d_{\mathrm{b}} \cdot f_{\mathrm{ym}}}{\sqrt{f_{\mathrm{cm}}}}
\end{aligned}
$$

The calculation of the curvature at yield $\varphi_{\mathrm{y}}$, the curvature at ultimate $\varphi_{\mathrm{u}}$ and the yield moment $M_{\mathrm{y}}$ of element end-sections was carried out with the module Section Designer of the analysis program SAP2000 [17]. The unconfined and confined model for the concrete follows the constitutive relationship of the uniaxial model proposed by Mander et al. [18], while the steel reinforcement is represented by a simple (parabolic at strainhardening region) model [19]. The axial force of the vertical resisting elements, that is used for the calculation of $\varphi_{\mathrm{y}}$, is determined from the (seismic) combination $G+0.3 Q$, where $G$ is the permanent and $Q$ is the live vertical load respectively. The shear span $L_{\mathrm{v}}$ was assumed equal to the half clear length $L_{\mathrm{cl}}$ of the structural elements along the frame bending planes except the strong direction of walls and the direction of columns with cantilever bending (six columns of the second wing $135^{\circ}$ ), where it was considered equal to $L_{\mathrm{cl}}$. The secant stiffness $E I_{\text {sec }}$ at yield (Equation 12) is calculated as percentage of the geometric stiffness $E I_{\mathrm{g}}$. It is equal to an average of $11 \%$ for the columns along frame bending planes, $17 \%$ for columns along cantilever bending planes, $11 \%$ for the strong wall direction, $12 \%$ for the weak wall direction and $10 \%$ for the beams, where the average modulus $E_{\mathrm{cm}}$ of concrete $\mathrm{C} 25 / 30$ was considered equal to $31 \mathrm{GPa}$ [16]. For the calculation of the plastic capacity $\theta_{\mathrm{pl}}$ in terms of chord rotations the equation $\theta_{\mathrm{pl}}=\left(\varphi_{\mathrm{u}}-\varphi_{\mathrm{y}}\right) \cdot L_{\mathrm{pl}}$ is used, where $L_{\mathrm{pl}}$ is calculated from equation (A.9) of EN 1998-3. In the non-linear analysis model, point plastic hinges were inserted at each end-section of all structural members. Interacting $P-M_{2}-M_{3}$ hinges and $M_{3}$ hinges are assigned to vertical elements and beams respectively.

The asymmetric singe-storey $\mathrm{R} / \mathrm{C}$ building has static eccentricities $e_{\mathrm{R}, \mathrm{Isec}}=6.02$ and $e_{\mathrm{R}, \mathrm{IIsec}}=1.95 \mathrm{~m}$ along the horizontal axes $I_{\mathrm{sec}}$ and $I I_{\mathrm{sec}}$ (location of the $\mathrm{CR}_{\mathrm{sec}}$ relative to $\mathrm{CM}$ ) which are rotated by $-24^{\circ}$ relative to the Cartesian $\mathrm{x}$, y axes [13,14] (Figure 5) and the building is characterized as torsional sensitive since $r_{\mathrm{I}, \mathrm{sec}} / r_{\mathrm{m}}=$ $0.94<1.10$ applies $[3,4,15]$, where the torsional radius $r_{\mathrm{I}, \mathrm{sec}}$ refers to $\mathrm{CR}_{\mathrm{sec}}$ (Table 4$)$. The periods of the three coupled modes are $\mathrm{T}_{1}=0.363 \mathrm{sec}, \mathrm{T}_{2}=0.326 \mathrm{sec}$ and $\mathrm{T}_{3}=0.226 \mathrm{sec}$.

In the non-linear analysis model, the accidental eccentricity along the axes $I_{\text {sec }}$ and $I I_{\text {sec }}$ is taken with a value equal to $5 \%$ of the maximum plan dimension normal to the loading direction:

$$
\begin{aligned}
& e_{\mathrm{a}, \mathrm{Isec}}= \pm 0.05 \cdot L_{\mathrm{Isec}}= \pm 0.05 \cdot 40.33= \pm 2.02 \mathrm{~m} \\
& e_{\mathrm{a}, \mathrm{IIsec}}= \pm 0.05 \cdot L_{\mathrm{IIsec}}= \pm 0.05 \cdot 31.72= \pm 1.59 \mathrm{~m}
\end{aligned}
$$

where, $L_{\mathrm{I}, \mathrm{sec}}=40.33 \mathrm{~m}$ and $L_{\mathrm{II}, \mathrm{sec}}=37.46 \mathrm{~m}$ are the maximum plan dimensions (Figure 5).

\section{Calculation of the floor enforced-displacements and inelastic design eccentricities}

The floor enforced-displacements of the proposed Direct Displacement-Based pushover procedure are determined as follows: 
The proposed value of the floor angular deformation $\gamma_{\mathrm{CR}, \mathrm{sec}}$ is obtained From Figure 1, corresponding to dual torsionally flexible buildings for normalized static eccentricities $e_{\mathrm{R}, \mathrm{IIsec}} / L_{\mathrm{IIsec}}=0.052$ or $e_{\mathrm{R}, \mathrm{Isec}} / L_{\mathrm{Isec}}=0.149$, respectively. Then, the floor enforced-translations on $\mathrm{CR}_{\text {sec }}$ along the axis $I_{s e c}$ and $I I_{\mathrm{sec}}$ are calculated:

$$
\begin{aligned}
& \psi_{\mathrm{I}, \mathrm{sec}}=\gamma_{\mathrm{CR}, \mathrm{Isec}} \cdot h=0.030 \cdot 3=0.090 \mathrm{~m} \\
& \psi_{\mathrm{II}, \mathrm{Sec}}=\gamma_{\mathrm{CR}, \mathrm{IIsec}} \cdot h=0.022 \cdot 3=0.066 \mathrm{~m}
\end{aligned}
$$

where $\gamma_{\mathrm{CR} \text {,Isec }}=0.03, \gamma_{\mathrm{CR} \text {,IIsec }}=0.022$ are the proposed floor angular deformations on $\mathrm{CR}_{\text {sec }}$ along the axis $I_{\text {sec }}$ and $I I_{\text {sec }}$ respectively and $h=3 \mathrm{~m}$ is the height of the single-storey building.

Additionally, the proposed values of floor enforced-rotations about vertical axis, for the stiff and flexible sides respectively, are obtained from Figure 3. The proposed values are selected for dual torsionally flexible buildings and for normalized static eccentricity equal to $e_{\mathrm{R}, \mathrm{Isec}} / L_{\mathrm{Isec}}=0.149$, from which the maximum values of enforcedrotations are determined:

$$
\psi_{\mathrm{R}, \mathrm{stiff}}=0.0015 \mathrm{rad}, \psi_{\mathrm{R}, \mathrm{flex}}=0.0034 \mathrm{rad}
$$

Finally, the floor enforced-rotations are inserted in the (16) loading combinations of Tables 2 and 3 with the appropriate signs shown in Table 1 , where $\mathrm{CR}_{\text {sec }}$ in-plan position is inside quadrant 1 according to Figure 2 . For example, with reference to Figure 5, in the first loading combination "+" $\psi_{\mathrm{I}} "+" 0.3 \cdot \psi_{\mathrm{II}}$ " - " $\psi_{\mathrm{R}, \text { stiff }}$ along the main principal axis $I_{\text {sec }}$ (Table 2), the floor enforced-rotation $\psi_{\mathrm{R}, \text { stiff }}$ is inserted with negative sign in order to predict the seismic demand of the building stiff side along $I_{s e c}$ axis (upwards side). On the contrary, the floor enforcedrotation $\psi_{\mathrm{R}, \text { flex }}$ of the second combination $"+" \psi_{\mathrm{I}} "+" 0.3 \cdot \psi_{\mathrm{II}} "+" \psi_{\mathrm{R}, \text { flex }}$ along the main principal axis $I_{\text {sec }}$ is inserted with positive sign in order to predict the seismic demand of the building flexible side along $I_{\text {sec }}$ axis (downwards side). Similarly, in the third loading combination " - "0.3 $\psi_{\mathrm{I}} "+" \psi_{\mathrm{II}} "+" \psi_{\mathrm{R}, \text { stiff }}$ along the main principal axis $I I_{\text {sec }}$ (Table 3), the floor enforced-rotation $\psi_{\mathrm{R} \text {,stiff }}$ is inserted with positive sign in order to predict the seismic demand of the building stiff side along $I I_{\text {sec }}$ axis (right side). On the contrary, in the fourth loading combination " - "0.3 $\cdot \psi_{\mathrm{I}} "+" \psi_{\mathrm{II}} "$ - " $\psi_{\mathrm{R}, \text { flex }}$ along the main principal axis $I I_{\text {sec }}$, the floor enforced-rotation $\psi_{\mathrm{R}, \text { flex }}$ is inserted with negative sign in order to predict the seismic demand of the building flexible side along $I I_{\text {sec }}$ axis (left side). Reversed signs for $\psi_{\mathrm{R} \text {,stiff }}$ and $\psi_{\mathrm{R} \text {,flex }}$ are considered in the loading combinations along the negative directions of $I_{\text {sec }}$ or $I I_{\text {sec }}$ axis.

With reference to the proposed Forced-Based pushover procedure, the calculation of the inelastic dynamic eccentricities $e_{\text {stif }}$ and $e_{\text {flex, }}$ (Equations 1-2 for buildings with torsional sensitivity) along each horizontal "Capable Near Collapse Principal Directions" $I_{s e c}$ and $I I_{\text {sec }}$ as well as of the inelastic design eccentricities $e_{1}, e_{2}$ (Equations 5-6) along the direction $I_{s e c}$ and $e_{3}, e_{4}$ (Equations 7-8) along the direction $I I_{\mathrm{sec}}$, which are used for the application of the proposed pushover analysis method on the asymmetric single-storey R/C building (see Figure 7), is performed step by step as follows:

1) Stiffness eccentricity $\left(\mathrm{CR}_{\mathrm{sec}}\right): e_{\mathrm{R}, \mathrm{Isec}}=6.02$ and $e_{\mathrm{R}, \mathrm{IIsec}}=1.95 \mathrm{~m}$

2) Storey Mass: $m=1103 \mathrm{tn}$

3) Mass moment of inertia: $J_{m}=222958 \mathrm{tn} \cdot \mathrm{m}^{2}$

4) Radius of gyration: $r_{m}=\sqrt{J_{\mathrm{m}} / m}=\sqrt{222958 / 1103}=14.22 \mathrm{~m}$

5) Min torsional radius: $r_{\mathrm{I}, \mathrm{sec}}=13.32 \mathrm{~m}$

6) Torsional Sensitivity: $r_{\mathrm{I}, \mathrm{sec}} / r_{m}=0.94<1.10 \rightarrow$ Torsional sensitive

7) Accidental Eccentricity (Equations 15-16): $e_{\mathrm{a}, \mathrm{Isec}}=2.02 \mathrm{~m}$ and $e_{\mathrm{a}, \mathrm{IIsec}}=1.59 \mathrm{~m}$

8) Inelastic Dynamic Eccentricities (Equations 1-2):

$$
\begin{aligned}
& e_{\text {stif,Isec }}=0.046 \cdot e_{\mathrm{RI}, \mathrm{sec}}-0.11 \cdot r_{m}=0.046 \cdot 6.02-0.11 \cdot 14.22=-1.29 \mathrm{~m} \\
& e_{\mathrm{stif} \text { IIsec }}=0.046 \cdot e_{\mathrm{RII}, \mathrm{sec}}-0.11 \cdot r_{m}=0.046 \cdot 1.95-0.11 \cdot 14.22=-1.47 \mathrm{~m} \\
& e_{\mathrm{flex}, \mathrm{Isec}}=0.84 \cdot e_{\mathrm{RI}, \mathrm{sec}}+0.12 \cdot r_{m}=0.84 \cdot 6.02+0.12 \cdot 14.22=6.76 \mathrm{~m} \\
& e_{\mathrm{flex}, \mathrm{IIsec}}=0.84 \cdot e_{\mathrm{RII}, \mathrm{sec}}+0.12 \cdot r_{m}=0.84 \cdot 1.95+0.12 \cdot 14.22=3.35 \mathrm{~m} \\
& \text { 9) Inelastic Design Eccentricities (Equations 5-8): } \\
& e_{1}=e_{\text {flex,Isec }}+e_{\mathrm{a}, \text { Isec }}=6.76+2.02=8.78 \mathrm{~m} \text { from } \mathrm{CR}_{\mathrm{sec}} \text { towards the flexible side of plan along } I_{\text {sec }} \\
& e_{2}=e_{\text {stiff,Isec }}-e_{\mathrm{a}, \text { Isec }}=-1.29-2.02=-3.31 \mathrm{~m} \text { from } \mathrm{CR}_{\mathrm{sec}} \text { towards the stiff side of plan along } I_{\text {sec }} \\
& e_{3}=e_{\text {flex,IIsec }}+e_{\mathrm{a}, \mathrm{IIsec}}=3.35+1.59=4.93 \mathrm{~m} \text { from } \mathrm{CR}_{\mathrm{sec}} \text { towards the flexible side of plan along } I I_{\text {sec }} \\
& e_{4}=e_{\text {stiff,IIsec }}-e_{\mathrm{a}, \text { IIsec }}=-1.47-1.59=-3.06 \mathrm{~m} \text { from } \mathrm{CR}_{\mathrm{sec}} \text { towards the stiff side of plan along } I I_{\text {sec }}
\end{aligned}
$$

\section{Seismic assessment}


In this section, the proposed methods of documented application of pushover analysis on the asymmetric singlestory $\mathrm{R} / \mathrm{C}$ building are described in detail. All results by pushover analysis compare with the seismic demand ones (target displacement) by nonlinear response history analysis which is also referred.

\subsection{Proposed pushover procedures}

1) According to the proposed Direct Displacement-Based pushover analysis, the procedure to be performed is illustrated in Figure 6 by applying the sixteen (16) combinations of the floor enforced-displacements of Tables 2 and 3 and finally take the envelope of the results. It is noted again that the floor enforced-rotations for the stiff and flexible sides of the building are entering in the loading combinations with the appropriate sign shown in Table 1, in order to maximize the ductility demands of the stiff or flexible sides of the building along the $I_{\text {sec }}$ or $I_{\text {sec }}$ axes.

2) According to the proposed Force-Based pushover analysis, the procedure to be performed is shown in Figure 7. In this figure the proposed methodology is appropriately formulated and performed as described below:

a) The appropriate inelastic dynamic eccentricities along each horizontal "Capable Near Collapse Principal Directions" $I_{\text {sec }}$ or $I I_{\text {sec }}$ are calculated by Equations (1-2) which are then introduced into Equations (5-8) to determine the inelastic design eccentricities $e_{1}, e_{2}$ and $e_{3}, e_{4}$ used for the application of the floor lateral static force along the axes $I I_{\mathrm{sec}}$ and $I_{\mathrm{sec}}$ respectively (as described in detail in section 4),

b) In total, for both horizontal directions $I_{\text {sec }}$ and $I I_{\text {sec }}$, eight pushover analyses are obtained considering the two signs $(+,-)$ of application of the floor lateral static loads.

The displacement results along the horizontal "Capable Near Collapse Principal Directions" $I_{\text {sec }}$ or $I I_{\text {sec }}$ of the eight separate pushover analyses are combined with the SRSS rule, in that step of the analyses where the seismic target-displacement at the lateral load application point is achieved, and from the sixteen combinations the envelope is taken.
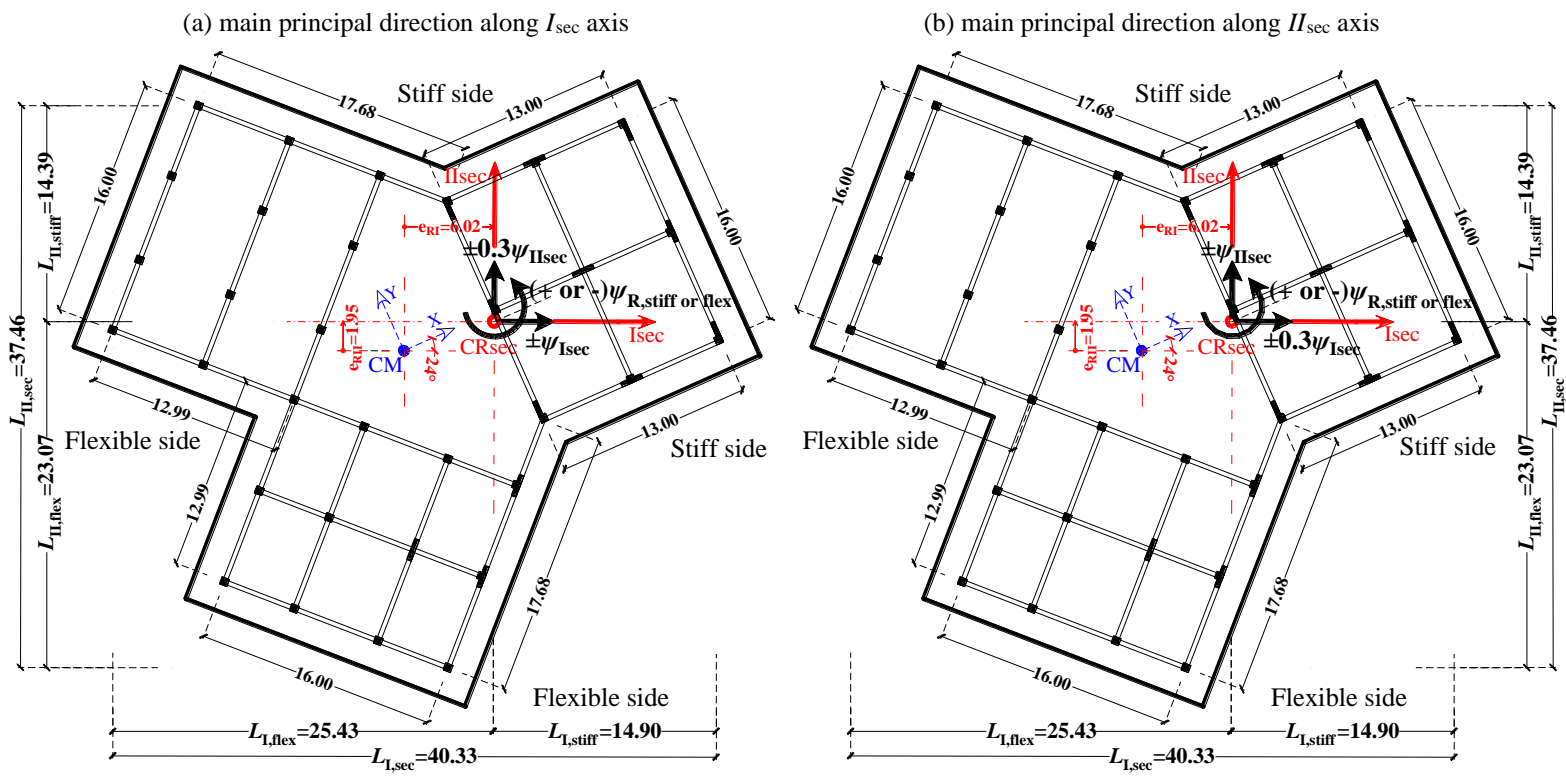

Fig. 6. Proposed Displacement-Based pushover using floor enforced-displacements (16 load combinations).

For comparison purposes, Figure 8 also shows the process of applying the pushover analysis according to EN 1998-1 [1], i.e. by applying the floor lateral static force on the location of the Mass Centre (CM) moved by the floor accidental eccentricity. It is worthy note that the locations in the plan of the lateral static forces of the proposed Forced-Based pushover procedure are in fully disagreement with Eurocode EN 1998-1.

Also, in Figure 9, by the recently international literature using a fully different methodology, the pushover analysis according to the "corrective eccentricity method" by Bosco et al. [8-10] is illustrated, where the corrective eccentricities $e_{\mathrm{c}, \text { Isec }}$ and $e_{\mathrm{c}, \text { IIsec }}$ for the building stiff sides (for loading along the horizontal axes $I I_{\text {sec }}$ and $I_{\text {sec }}$ respectively) have been calculated, plus the accidental eccentricities. For the building flexible sides, only the accidental eccentricities are used according to the method. Thus, our investigative results are very compatible with Bosco's ones.

In Figures 7, 8 and 9, the sixteen SRSS combinations of the eight separate pushover analyses, from which the envelope of the displacement results along the horizontal axes $I_{\text {sec }}$ and $I I_{\text {sec }}$ is calculated, are as follows:

(1) $\oplus(5),(1) \oplus(6),(1) \oplus(7),(1) \oplus(8)$ and $(2) \oplus(5),(2) \oplus(6),(2) \oplus(7),(2) \oplus(8)$ and (3) $\oplus(5)$, (3) $\oplus$ (6), (3) $\oplus(7),(3) \oplus(8)$ and (4) $\oplus(5),(4) \oplus(6),(4) \oplus(7),(4) \oplus(8)$. 
The capacity curves resulted from the pushover analyses according to EN 1998-1 (Figure 8) and to the proposed Force-Based procedure (Figure 7), are presented in Figures 10 and 11, respectively.

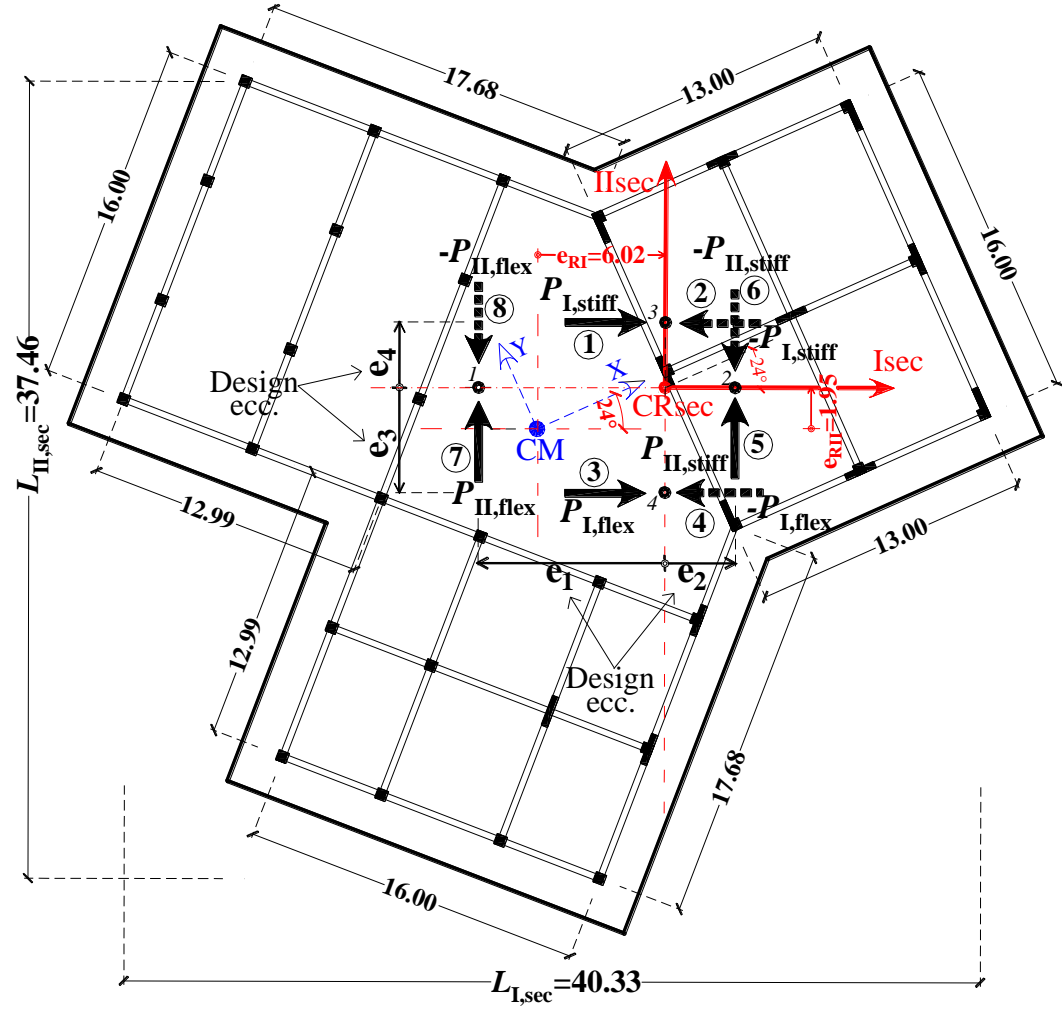

Fig. 7. Proposed Forced-Based procedure of pushover analysis using the inelastic design eccentricities in order to apply the floor lateral static forces (8 separate pushover analyses).

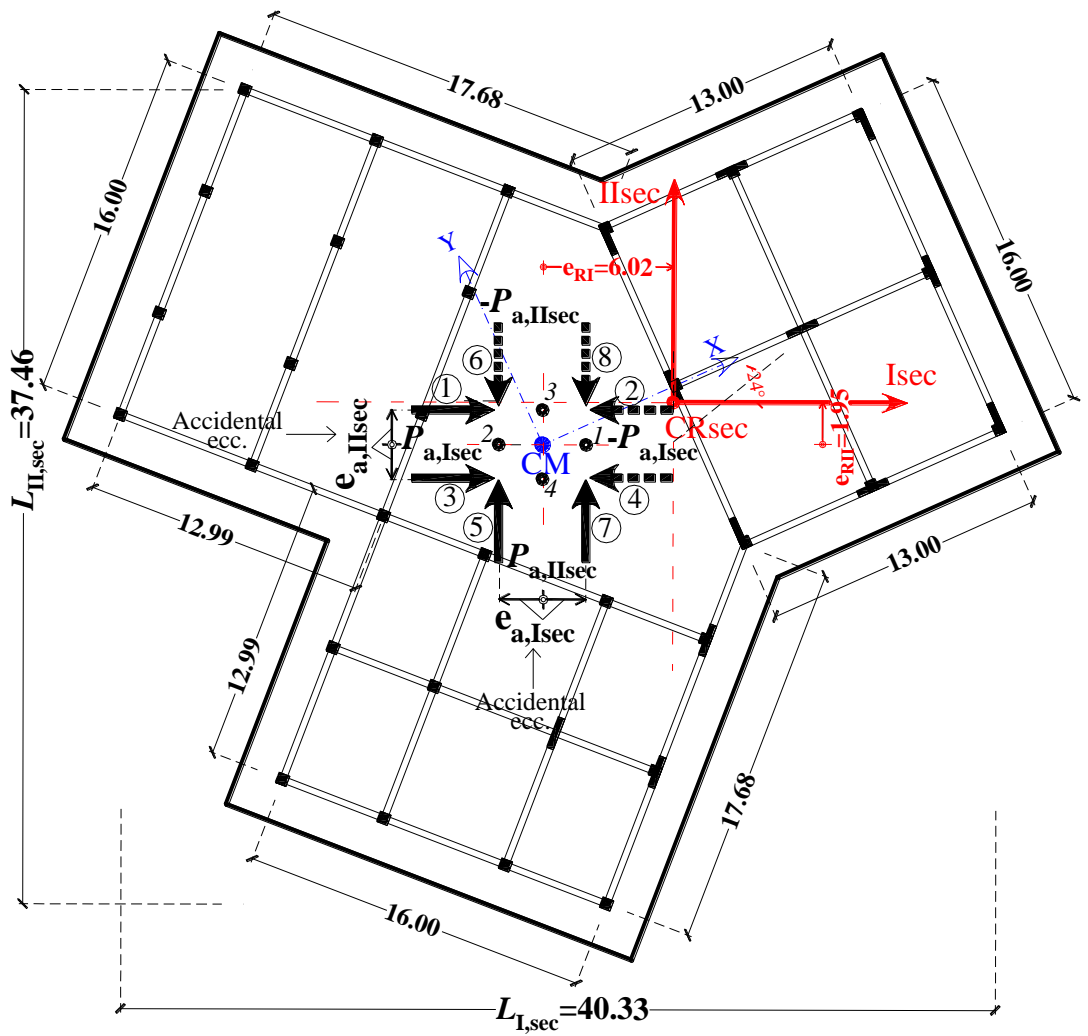

Fig. 8. Pushover analysis according to EN 1998-1 on the asymmetric single-storey R/C building. 


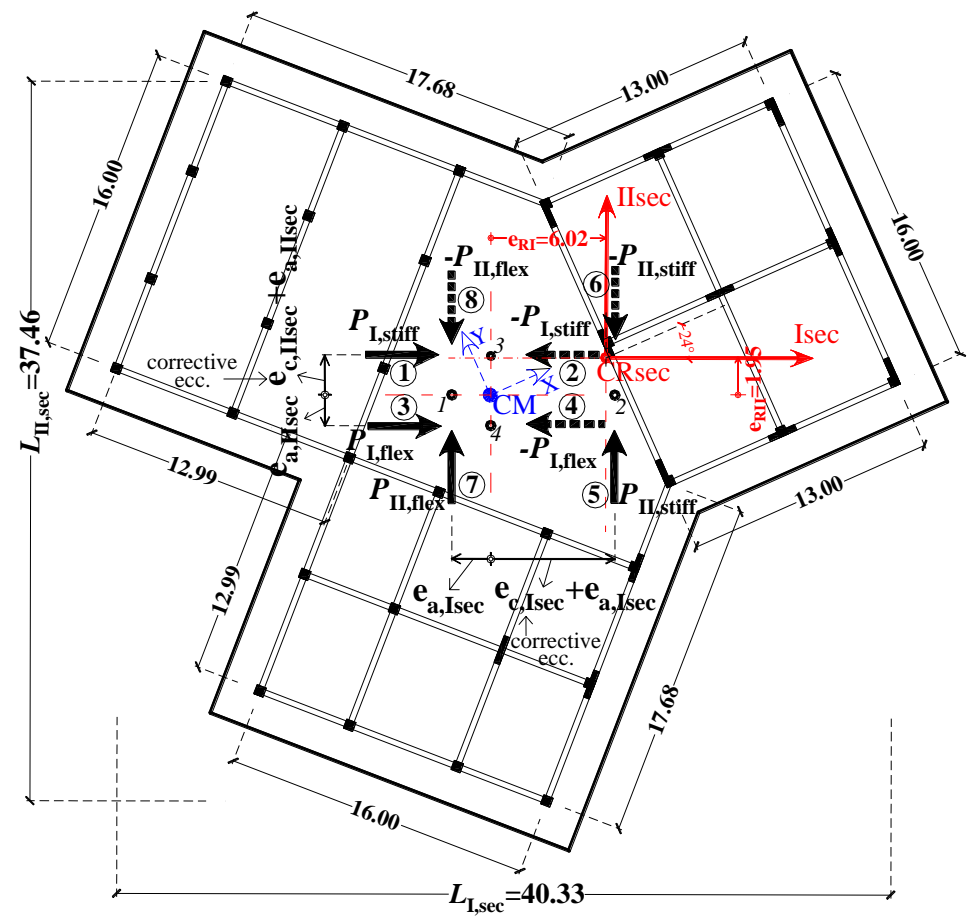

Fig. 9. Pushover analysis according to the "corrective eccentricity method", Bosco et al (2017).

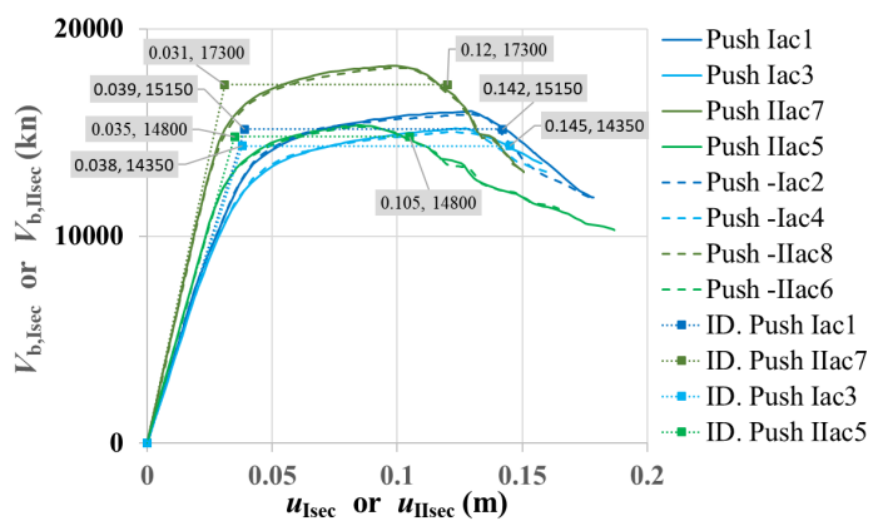

Fig. 10. Capacity curves of pushover analysis according to EN 1998-1.

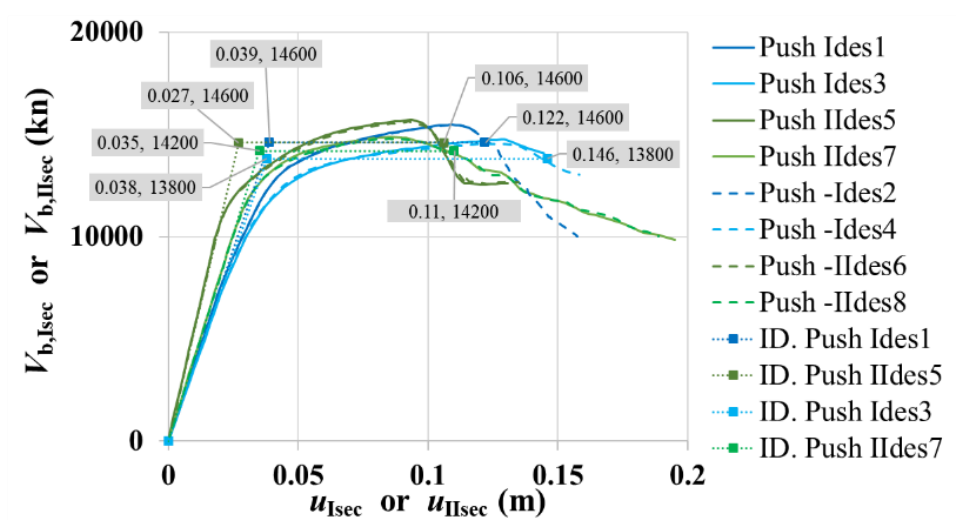

Fig. 11. Capacity curves of pushover analysis according to the proposed Forced-Based method

\subsection{Non-linear response history analysis}

In the context of the current work, the "seismic target-displacement" is calculated by performing non-linear response history analysis (N-LRHA). According to EN 1998-1, N-LRHA analysis is performed in a (non-linear) model resulting from the simultaneous movement of the Mass Centre CM by each accidental eccentricity along 
the horizontal "Capable Near Collapse Principal Directions" $I_{\text {sec }}$ and $I I_{\text {sec }}$ (Equations 15-16), which constitute the appropriate principal directions. Of the four sign combinations of the two accidental eccentricities $e_{\mathrm{a}, \mathrm{I}}$ and $e_{\mathrm{a}, \mathrm{II}}$, four displaced CM positions are defined. Three pairs of horizontal accelerograms [3], consisting of five artificial accelerograms (created by Seismosoft [20]), are used that have similar characteristics with the Hellenic tectonic faults [21]. Each accelerogram has an elastic acceleration response spectrum practically equal to the corresponding design spectrum of EN 1998-1 for soil class D (Figure 12). Each pair is rotated about the vertical axis successively per $22.5^{\circ}$, to find the worst seismic load state [22] of the $16 \mathrm{~N}$-LRHA obtained for each pair. The two seismic components of each pair were scaled to a PGA level approximately equal to $1 \mathrm{~g}$, resulting in the Near Collapse state of this building. Finally, the envelope of the displacements along the axes $I_{\text {sec }}$ and $I I_{\text {sec }}$ from all these NLRHA (192) was the "seismic target-displacement" for each control point in plan.
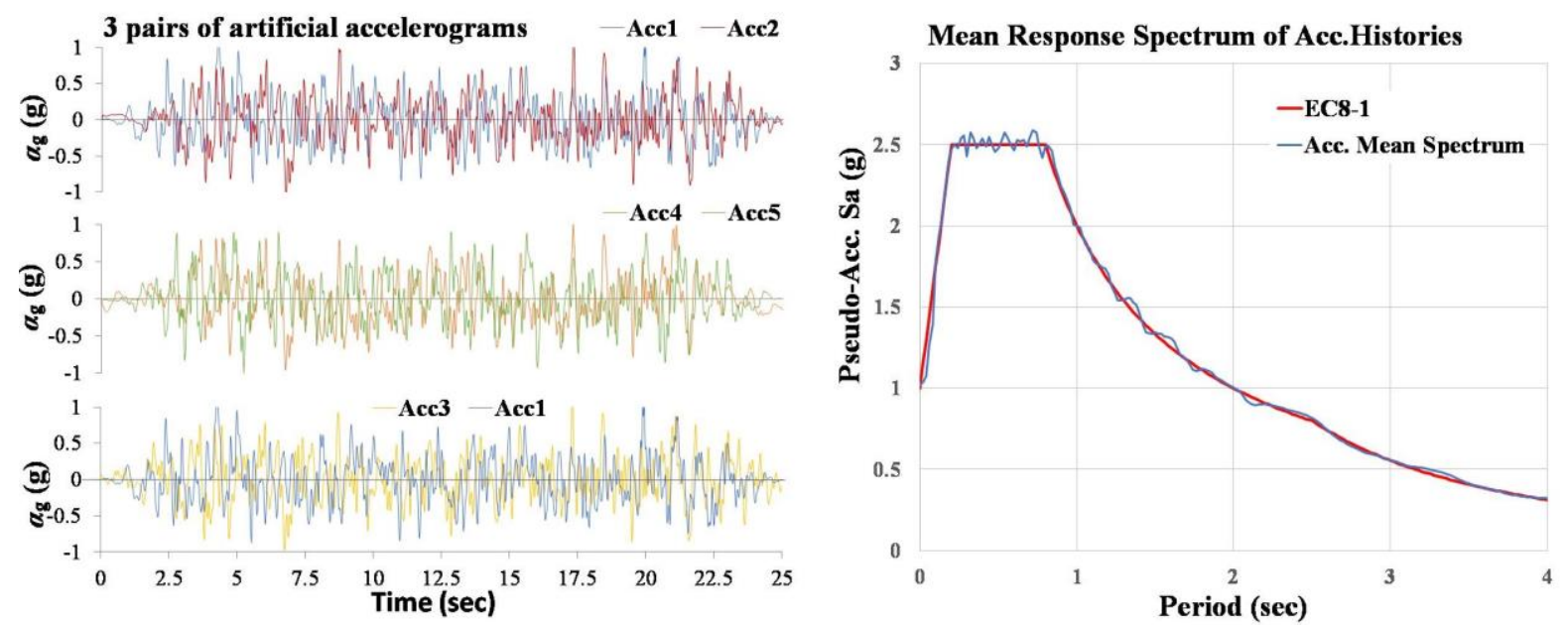

Fig. 12. Three pairs of unit-normalized artificial accelerograms and their mean elastic acceleration spectrum with reference to spectrum of EN 1998-1 (damping ratio $0.05, a_{\mathrm{g}} \cdot S=1 \mathrm{~g}$ and soil D).

\section{Results of non-linear analysis methods}

The seismic inelastic displacements of the building along the "Capable Near Collapse Principal Axes" $I_{\text {sec }}$ and $I I_{\text {sec }}$ resulting from the non-linear analysis methods of sections 5.1 and 5.2, i.e. the non-linear response history analysis (N-LRHA), the proposed pushover analysis procedures, the pushover analysis according to EN 1998-1 as well as the "corrective eccentricity method" of pushover analysis (Bosco et al [8-10]), are presented here for comparison purposes. The results are illustrated in Figures 13 and 14 in terms of plan inelastic displacement profile. The benchmark is represented by the displacement demand given by the N-LRHA.

First, it is observed that that the proposed Direct Displacement-Based procedure predicts with safety the displacements of the building flexible and stiff sides (Figure 13). Only the displacement $u_{\mathrm{II}, \mathrm{sec}}$ of the building stiff side along axis $I I_{\text {sec }}$ is predicted more conservatively. This over-estimation of the building stiff-side displacement along axis $I I_{\text {sec }}$ drives to higher seismic ductility demand on this side, fact that has not great importance.

It is also observed that, relative to the displacement results from N-LRHA (seismic target-displacement), the displacement of the stiff side $u_{\mathrm{I}, \mathrm{sec}}$ along the horizontal axis $I_{\mathrm{sec}}$ resulted from the pushover analysis according to EN 1998-1 is lower by $12 \%$ (Figure 14). Similarly, the displacements $u_{\mathrm{I}, \mathrm{sec}}$ and $u_{\mathrm{II}, \mathrm{sec}}$ of the flexible side along the axes $I_{\mathrm{sec}}$ and $I I_{\mathrm{sec}}$ are a little lower by $4 \%$ and $2 \%$ respectively. On the contrary, the displacement of the stiff side $u_{\mathrm{II}, \mathrm{sec}}$ along the horizontal axis $I I_{\text {sec }}$ resulted from all pushover method of analysis is predicted with safety. Furthermore, it is noted that the proposed Force-Based method of pushover analysis provides the displacement of the stiff side $u_{\mathrm{I}, \mathrm{sec}}$ along the horizontal axis $I_{\mathrm{sec}}$ with a safety margin of $11 \%$ and the displacements $u_{\mathrm{I}, \mathrm{sec}}$ and $u_{\mathrm{II} \text { sec }}$ of the flexible side along the horizontal axes $I_{\text {sec }}$ and $I I_{\text {sec }}$ also with a safety margin $2 \%$ and $1 \%$, respectively.

It is worthy noted that, relative to the displacement results of the N-LRHA, the "corrective eccentricity method" of pushover analysis gives non-conservative results by $10 \%$ for the displacement $u_{\mathrm{I} \text {,sec }}$ of the stiff side along the $I_{\text {sec }}$ axis (Figure 14). Similar results, such as the EN1998-1 pushover method, apply to the displacements $u_{\mathrm{I}, \mathrm{sec}}$ and $u_{\mathrm{II}, \mathrm{sec}}$ of the flexible sides along the axes $I_{\mathrm{sec}}$ and $I I_{\mathrm{sec}}$, i.e. lower by $4 \%$ and $2 \%$, respectively. This is due to the fact that, according to the method, only the accidental eccentricity is used to apply the lateral static forces in order to predict the flexible side displacements. 
It is concluded that, the proposed Forced-Based pushover methodology of the present paper is more accurate than the pushover method that uses the "corrective eccentricities"; however, the later method, that is based on the corrective eccentricities, certainly drives in compatible results with our parametric analysis. On the contrary, the pushover analysis according to EN 1998-1 is exceptionable.

Plan displacement profile $u_{\text {IIsec }}$

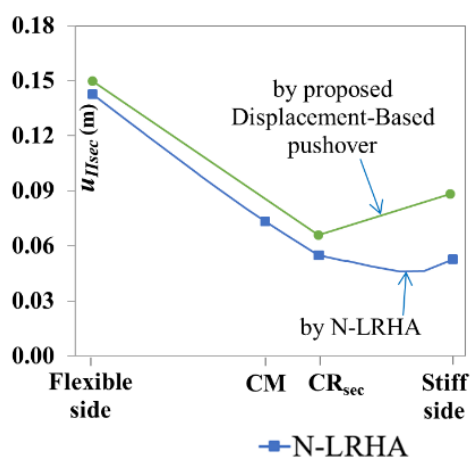

Plan displacement profile $u_{\mathrm{Isec}}$

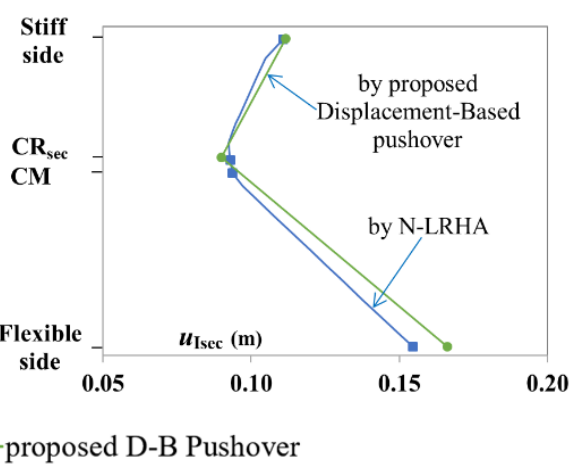

Fig. 13. Plan inelastic displacement profile along the "Capable Near Collapse Principal Axes" $I I_{\text {sec }}($ left) and $I_{\text {sec }}$ (right) resulted from the proposed Direct Displacement-Based pushover procedure.

Plan displacement profile $u_{\text {IIsec }}$

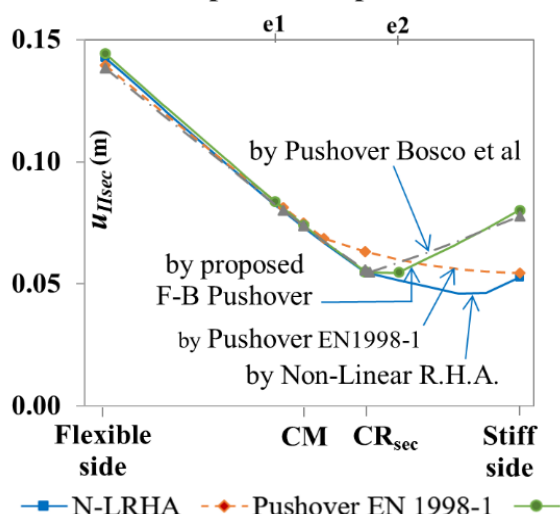

Plan displacement profile $u_{\text {Isec }}$

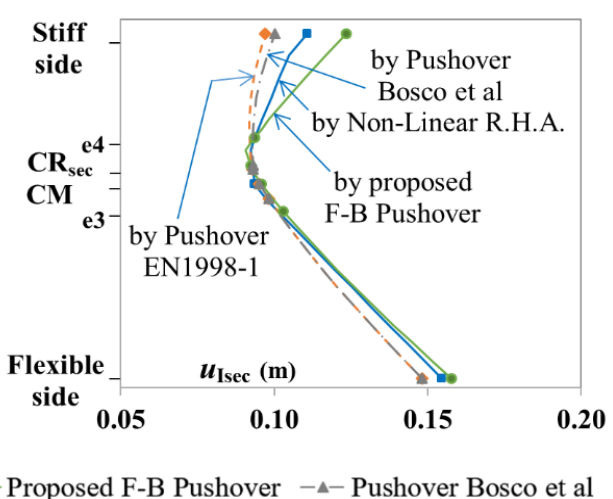

Fig. 14. Plan inelastic displacement profile along the "Capable Near Collapse Principal Axes" $I I_{\text {sec }}($ left) and $I_{\text {sec }}$ (right) resulted from the proposed Forced-Based pushover procedure.

\section{Conclusions}

In this paper, two new proposed procedures of documented application of pushover analysis on asymmetric single-story R/C buildings have been presented in detail, aiming directly at the Near Collapse state. The first proposed pushover procedure is a Direct Displacement-Based one using floor enforced-displacements as action while the second one is Forced-Based applying the floor lateral static forces eccentrically to CM using inelastic dynamic eccentricities.

To clarify and evaluate the proposed procedures, a single-storey R/C building has been assessed. The building is double-asymmetric and torsional sensitive. To apply the proposed procedures, the non-linear model of the building has been formed, in which the structural members have been provided with their secant stiffness $E I_{\text {sec }}$ at yield. Then, the following have been calculated: (a) the in-plan location of the "Capable Near Collapse Centre of Stiffness" $\mathrm{CR}_{\mathrm{sec}}$, (b) the orientation of the horizontal "Capable Near Collapse Principal Axes" $I_{\text {sec }}$ and $I I_{\text {sec }}$, (c) the "Capable Near Collapse Torsional Radii" $r_{\mathrm{I}, \mathrm{sec}}$ and $r_{\mathrm{II}, \mathrm{sec}}$ relative to the horizontal axes $I_{\text {sec }}$ and $I I_{\text {sec }}$ as well as the radius of gyration $r_{\mathrm{m}}$ of the diaphragm, and (d) the torsional sensitivity of the model according to the relationship $r_{\mathrm{I}, \mathrm{sec}}$ or $r_{\mathrm{II}, \mathrm{sec}} \leq 1.10 r_{\mathrm{m}}$. Finally, using the previous data, the inelastic dynamic eccentricities plus the accidental ones, namely the inelastic design eccentricities of the Forced-Based pushover procedure, have been calculated from Equations (1-4) and (5-8), respectively. Also, the floor enforced displacements of the Displacement-Based procedure are determined using Figures 1 and 3.

The process of applying the proposed procedures of pushover analyses, using either the floor enforceddisplacements $\psi_{\mathrm{I} s e c}, \psi_{\mathrm{IIsec}}$ and $\psi_{\mathrm{R} \text {,(stiff or flex) }}$ or the design eccentricities $e_{1}, e_{2}$ and $e_{3}, e_{4}$ along each horizontal 
direction $I_{\text {sec }}$ and $I I_{\text {sec }}$ respectively, has been illustrated in detail in Figures 6 and 7. In this work, the seismic target-displacement of each control point of the diaphragm has been calculated by non-linear response history analysis (N-LRHA). The floor plan inelastic displacement profile along each horizontal direction $I_{\text {sec }}$ and $I I_{\text {sec }}$ resulting from N-LRHA has been compared with the corresponding ones from pushover analysis according to EN 1998-1, from the proposed procedures of pushover analysis and from the pushover that use the "corrective eccentricities" [8-10].

The main conclusions are the following:

1) The application of the pushover analysis method according to EN 1998-1 (Figure 8) results in nonconservative displacement $u_{\mathrm{I} \text {,sec }}$ (by 12\%) of the building stiff side along the horizontal axis $I_{\text {sec }}$. Also, the displacements of the building flexible sides along both the horizontal directions $I_{\text {sec }}$ and $I I_{\text {sec }}$ are a little lower relative to seismic demand. This due to wrong location in the plan of the floor lateral static forces during the pushover procedure.

2) The proposed Direct Displacement-Based pushover procedure (on the numerical examples where have been examined) provides safe estimates for the displacements of the building flexible and stiff sides. Higher conservative values were observed only on the building stiff-side along $I I_{\text {sec }}$ axis. This overestimation of the building stiff-side displacements drives to higher seismic ductility demand on this side, fact that has not great importance.

3) The proposed Forced-Based procedure of pushover analysis (Figure 7) predicts with safety all the inelastic displacements throughout the floor-plan. More specifically, the displacement $u_{\mathrm{I}, \mathrm{sec}}$ of the building stiff side along the horizontal axis $I_{\text {sec }}$ is calculated with a safety margin of $11 \%$. Additionally, the displacements $u_{\mathrm{I}, \mathrm{sec}}$ and $u_{\mathrm{II}, \mathrm{sec}}$ of the building flexible sides along the horizontal axes $I_{\text {sec }}$ and $I I_{\text {sec }}$ are calculated with a safety margin of $1 \%$ and $2 \%$ respectively.

4) The "corrective eccentricity method" that have been proposed by Bosco et al [8-10] (Figure 9), in which the floor lateral loading is applying with less eccentricity than the design eccentricity of the proposed Force-Based pushover procedure, gives non-conservative results (by 10\%) for the displacement $u_{\mathrm{I}, \mathrm{sec}}$ of the stiff side along the $I_{\text {sec }}$ axis. Also, the displacements of the flexible side along both the horizontal axes $I_{\text {sec }}$ and $I I_{\text {sec }}$ remain a little lower compared with the seismic demand, as for EN1998-1, since "corrective eccentricity" is not used for the flexible side, except the accidental eccentricity.

Therefore, the two proposed procedures for the documented application of pushover analysis on asymmetric single-story R/C buildings, using either suitable floor enforced-displacements or more accurate inelastic design eccentricities, is a rational way to predict with safety the (real) coupling between the torsional vibrations (about vertical axis) of the floor-diaphragm with the translational ones under pure translational seismic excitation of the building's base, especially as regards the displacements of the stiff sides of the building. The proposed ForceBased pushover procedure of the present paper is more accurate than the pushover method that uses the "corrective eccentricities"; however, the later method that is based on the corrective eccentricities certainly drives in compatible results with our parametric analysis, general, but the present paper gives more accuracy. On the contrary, the locations in the plan of the floor lateral static forces into the framework of pushover analysis according to EN 1998-1 are fully inadequate.

\section{References}

[1] EN 1998-1. Eurocode 8: Design of structures for earthquake resistance - Part 1: General rules, seismic actions and rules for buildings. Authority: The European Union Per Regulation 305/2011, Directive 98/34/EC, Directive 2004/18/EC. 2004.

[2] EN 1998-3. Eurocode 8: Design of structures for earthquake resistance - Part 3: Assessment and retrofitting of buildings. Authority: The European Union Per Regulation 305/2011, Directive 98/34/EC, Directive 2004/18/EC. 2005.

[3] Bakalis A, Makarios T. Dynamic eccentricities and the "capable near collapse centre of stiffness" of reinforced concrete single-storey buildings in pushover analysis. Engineering Structures. 2018;166:62-78.

[4] Bakalis A, Makarios T. Seismic assessment of asymmetric single-story RC buildings by modified pushover analysis using the "capable near collapse centre of stiffness": Validation of the method. Journal of Earthquake Engineering. 2019. DOI:10.1080/13632469.2019.1698477.

[5] Bakalis A, Makarios T. Dynamic eccentricities in pushover analysis of asymmetric single-storey buildings. Seismic Behaviour and Design of Irregular and Complex Civil Structures III, Chapter 24, Geotechnical, Geological and Earthquake Engineering. Springer Publishing House; 2020.

[6] Bakalis A, Makarios T. Dynamic eccentricities in pushover analysis of asymmetric single-storey buildings. In: Proccedings of Eighth European Workshop on the Seismic Behaviour of Irregular and Compex Structures. Bucharest, Romania; 2017. 
[7] Makarios T, Bakalis A. Pushover analysis using suitable dynamic eccentricities on asymmetric single-storey buildings. In: Proc. of $16^{\text {th }}$ European Conference of Earthquake Engineering. Thessaloniki, Greece; 2018.

[8] Bosco M, Ghersi A, Marino EM. Corrective eccentricities for assessment by the nonlinear static method of 3D structures subjected to bidirectional ground motions. Earthquake Engineering \& Structural Dynamics. 2012;41:1751-1773.

[9] Bosco M, Ferrara GA, Ghersi A, Marino EM, Rossi PP. Predicting displacement demand of multistorey asymmetric buildings by nonlinear static analysis and corrective eccentricities. Engineering Structures. 2015;99:373-387.

[10] Bosco M, Ghersi A, Marino EM, Rossi PP. Generalized corrective eccentricities for nonlinear static analysis of buildings with framed or braced structure. Bulletin of Earthquake Engineering. 2017;15(11):4887-4913.

[11] Chopra A, Goel R. A modal pushover analysis procedure to estimate seismic demands for unsymmetric-plan buildings. Earthquake Engineering \& Structural Dynamics. 2004;33:903-927.

[12] Antoniou S, Pinho R. Development and verification of a displacement-based adaptive pushover procedure. Journal of Earthquake Engineering. 2004;8(5):643-661.

[13] Makarios T, Anastassiadis K. Real and fictitious elastic axis of multi-storey buildings: Theory. The Structural Design of Tall Buildings. 1998;7(1):33-55.

[14] Makarios T, Anastassiadis K. Real and fictitious elastic axis of multi-storey buildings: Applications. The Structural Design of Tall Buildings. 1998;7(1):57-71.

[15] Makarios T. Practical calculation of the torsional stiffness radius of multistorey tall buildings. Journal of the Structural Design of Tall \& Special Buildings. 2008;17(1):39-65.

[16] EN 1992-1-1. Eurocode 2: Design of concrete structures - Part 1-1: General rules and rules for buildings [Authority: The European Union Per Regulation 305/2011, Directive 98/34/EC, Directive 2004/18/EC]. 2004.

[17] CSI, SAP2000. Three dimensional static and dynamic finite element analysis and design of structures V16.0.2. Computers and Structures Inc.. Berkeley, CA, USA. 2013.

[18] Mander JB, Priestley MJ, Park R. Theoretical stress-strain model for confined concrete. Journal of Structural Engineering. 1988;114(8):1827-1849.

[19] Park R, Paulay T. Reinforced concrete structures. New York: John Wiley \& Sons, Inc; 1975.

[20] Seismosoft 2016. SeismoArtif - A computer program for generation of artificial accelerograms. Available from URL: www.seismosoft.com.

[21] Makarios T. Design characteristic value of the Arias intensity magnitude for artificial accelerograms compatible with Hellenic seismic hazard zones. International Journal of Innovative Research in Advanced Engineering. 2015;2(1):87-98.

[22] Athanatopoulou A, Doudoumis I. Principal directions under lateral loading in multistory asymmetric buildings. The Structural Design of Tall and Special Buildings. 2008;17(4):773-794.

(C) 2020 by the author(s). This work is licensed under a Creative Commons Attribution 4.0 International License (http://creativecommons.org/licenses/by/4.0/). Authors retain copyright of their work, with first publication rights granted to Tech Reviews Ltd. 